\title{
Constraints on the sulfur subduction cycle in Central America from sulfur isotope compositions of volcanic gases
}

\author{
J. Maarten de Moor ${ }^{\mathrm{a}, \mathrm{b},{ }^{*},}$, Tobias P. Fischer ${ }^{\mathrm{b}}$, Terry Plank $^{\mathrm{c}}$ \\ ${ }^{a}$ Observatorio Vulcanológico y Sismológico de Costa Rica, Universidad Nacional, Heredia, Costa Rica \\ ${ }^{\mathrm{b}}$ Department of Earth and Planetary Sciences, University of New Mexico, Albuquerque, NM, USA \\ ${ }^{\mathrm{c}}$ Lamont-Doherty Earth Observatory, Columbia University, Palisades, NY, USA
}

\section{A R T I C L E I N F O}

\section{Editor: Don Porcelli}

\section{Keywords:}

Sulfur isotopes

Volcanic gas emissions

Sulfur subduction cycle

Magma redox

Mantle sulfur

\begin{abstract}
A B S T R A C T
The sulfur cycle at convergent margins remains poorly constrained yet is fundamentally important for understanding the redox state of Earth's reservoirs and the formation of ore deposits. In this study we investigate the sulfur isotope composition of high temperature volcanic gases emitted from the Nicaraguan (average of $+4.8 \pm$ $1.3 \%$ ) and Costa Rican (average of $+2.3 \pm 1.3 \%$ ) arc segments contributing to emissions from the Southern Central American Volcanic Arc (SCAVA; average of $+3.8 \pm 1.7 \%$ ). Along-arc variations in geochemical tracers at SCAVA are widely accepted to reflect variations in subduction parameters and deep fluid sources and correlations between these parameters and gas $S$ isotope compositions are observed. These correlations suggest that gas emissions are sourced from a mixture of mantle $S$ with $\delta^{34} S \sim 0 \%$ and isotopically heavy slab-derived sulfur with $\delta^{34} \mathrm{~S} \geq \sim+8 \%$. We employ Monte Carlo mass balance modeling to constrain $\mathrm{S}$ inputs to the subduction zone and relative contributions from mantle and slab to arc sulfur emissions. The models indicate that bulk subduction input in Nicaragua has a S isotope composition of $+1.4 \pm 0.5 \%$ compared to $-0.2 \pm 0.4 \%$ in Costa Rica, requiring preferential release of isotopically heavy oxidized $S$ from the slab to explain the relatively high $\delta^{34} S$ observed in arc outputs. We show that the flux of $S$ from the slab is sufficient to oxidize the entire mantle wedge within the lifetime of the arc, indicating that $S$ is a primary oxidizing agent in subduction zones. Furthermore, the preferential removal of heavy $S$ from the slab requires retention of isotopically light $S$ in the residual slab. Subduction-scale fractionation of S isotopes is fundamentally important in explaining why Earth's bulk surface reservoirs are isotopically positive.
\end{abstract}

\section{Introduction}

Sulfur plays a fundamental role in the redox state of Earth's reservoirs and has played a key role in the evolution of life. The formation of many types of ore deposits depend on sulfur chemistry and transport (e. g. Evans and Tomkins, 2011; Sun et al., 2015). Large explosive volcanic eruptions can cause global climate cooling due to the injection of sulfur into the stratosphere (e.g. Sigurdsson, 1990), and understanding the degassing mechanisms of sulfurous gases is crucial for volcanic eruption forecasting using gas monitoring (e.g. Williams et al., 1990; Daag et al., 1996; Giggenbach, 1996; de Moor et al., 2016b,a). The dynamic nature of sulfur chemistry largely stems from its large range of valence states -2 to +6 and as such sulfur can act as an important reducing or oxidizing agent in geologic processes.

The subduction process provides the primary mechanism for formation of continental crust and modification of the Earth's deep mantle and is therefore fundamental to understanding global geochemical cycles. Here, oceanic crust, marine sediments, and lithospheric mantle form the slab that is subducted beneath the overriding plate. Volatiles released from metamorphic reactions driven by increasing $\mathrm{T}$ and $\mathrm{P}$ in the slab cause melting in the mantle wedge, forming arc magmas. These magmas are more oxidized than those formed at mid ocean ridges and intraplate settings (e.g. Kelley and Cottrell, 2009), typically carrying more water, sulfur, and metals.

The processes generating oxidized arc magmas at subduction zones remain controversial. The introduction of oxidized components such as ferric iron, sulfate, and carbonate to the mantle wedge may play a key role in this fundamental characteristic of arc magmatism (e.g. Evans, 2012). On the other hand, differentiation processes (crystallization, degassing, assimilation) may drive oxidation of more evolved arc

\footnotetext{
* Corresponding author at: Observatorio Volcanológico y Sismológico de Costa Rica (OVSICORI), Universidad Nacional, Heredia, Costa Rica.

E-mail address: joost.demoor@una.cr (J.M. de Moor).
} 
magmas (Lee et al., 2012; Lee et al., 2018). Deciphering these processes is fundamental to understanding the inherent explosivity of arc volcanoes, the formation of ore deposits, and Earth's geochemical cycles through time.

Stable isotope compositions of high temperature gases emitted during open vent degassing likely reflect the primary magmatic source composition linked to tectonic scale magma generation processes (e.g. Taran et al., 1995; Fischer et al., 2002; de Moor et al., 2013; Aiuppa et al., 2017), and are powerful tracers of source components at subduction zone volcanoes. Sulfur isotopes are particularly sensitive as source redox tracers due to the fact that the heavy isotope has a strong affinity for the more oxidized sulfur species (e.g. de Moor et al., 2013). Sulfur isotopes also fractionate between phases during extraction and differentiation processes as a function of temperature and the $S$ species present in the various phases involved (Marini et al., 2011). However, high temperature volcanic gases that have not lost significant $S$ likely represent source compositions, but few volcanoes globally presented adequate conditions for sampling (Fischer, 2008).

In recent compilations, Oppenheimer et al. (2014) and Kagoshima et al. (2015) presented $\delta^{34} \mathrm{~S}$ data from global arc volcanoes with high $\mathrm{T}$ gas emissions, showing that $\mathrm{S}$ isotope compositions of primary arc gases are positive, with values ranging between $+2 \%$ and $+10 \%$. Recently, Aiuppa et al., 2014, 2017, 2019 have shown that $\mathrm{CO}_{2} / \mathrm{S}_{\mathrm{T}}$ in gas emissions at open vent volcanoes is a proxy for deep volatile sources related to subduction parameters, with higher $\mathrm{CO}_{2} / \mathrm{S}_{\mathrm{T}}$ associated with greater slab contribution. Their models imply that $C$ is preferentially released from the slab with respect to $S$, and/or that $S$ is predominantly derived from ambient mantle. Significantly, however, Kagoshima et al. (2015) suggested that sulfur isotope compositions and $\mathrm{S} /{ }^{3} \mathrm{He}$ ratios vary among different subductions zones, proposing that $S$ isotopes and relative abundances in high temperature volcanic gases are dependent on subducted materials and not dominated by mantle wedge composition. This observation has important implications with regards to the potential of sulfur as the main oxidizing agent of the mantle wedge and arc magmas.

In this study we investigate $S$ isotope compositions of high temperature volcanic gases emitted at the Southern Central America Volcanic Arc (SCAVA). Here, dramatic along-arc geochemical transitions are observed in many trace element and isotope ratios, which are widely attributed to tectonic scale variations in subduction parameters such as slab dip, mantle composition, and subducted components (e.g. Carr et al., 1990; Protti et al., 1994; Patino et al., 2000; Fischer et al., 2002; Plank et al., 2002; Gazel et al., 2009). We show here that sulfur outputs at SCAVA are isotopically heavy, with higher $\delta^{34}$ S observed in Nicaragua than in Costa Rica. Subducted oceanic crust is heterogeneous with regards to $S$, and modeling of bulk sulfur inputs indicates that the total input is not drastically different from MORB S isotope composition. We argue through mass balance modeling that the observation that arc outputs are isotopically heavier than subduction inputs requires the preferential release of oxidized sulfur from the subducted slab beneath the arc and retention of isotopically light reduced sulfur in the deeply subducted slab. Sulfate-rich fluids released from the slab provide a powerful oxidizing agent in the mantle wedge contributing to the oxidized nature of basaltic arc magmas and our modeling allows quantification of the oxidizing potential of $S$ in slab fluids.

\section{Methods and results}

\subsection{Methods}

Volcanic gas samples were collected using both fumarole direct sampling techniques (Giggenbach and Goguel, 1989) and bubbler sampling of fumaroles and plumes (Menyailov et al., 1986; de Moor et al., 2013). Sodium hydroxide solution containing absorbed $\mathrm{S}$ gases was oxidized using $\mathrm{H}_{2} \mathrm{O}_{2}$ and $\mathrm{BaSO} 4$ was precipitated using $100 \mathrm{~g} / \mathrm{L}$ $\mathrm{BaCl}$ solution. Barium sulfate was separated from the solution by centrifuge, including multiple rinses using deionized water. Sulfur isotope measurements were conducted at the University of New Mexico by Continuous Flow Isotope Ratio Mass Spectrometry using the methods and standards detailed in de Moor et al. (2013). International standards (all $\mathrm{S}$ isotope values are reported relative to the Vienna Canyon Diablo Troilite scale (Robinson, 1995) in $\delta^{34} \mathrm{~S}_{\mathrm{V}-\mathrm{CDT}}$ notation; IAEA-S- $1=-0.3 \%$ $\left(\mathrm{Ag}_{2} \mathrm{~S}\right), \mathrm{NBS} 123=+17.44 \%$ (sphalerite), and NBS127 $=+21.10 \%$ (barium sulfate) were run at the beginning, at intervals between samples, and at the end of analytical sessions. Analytical precision calculated from the standards is better than $0.3 \%$ ( $1 \sigma)$.

\subsection{Sulfur isotope compositions}

Sulfur isotope compositions are reported in Table 1 for gas samples and scoria samples, including data available from the literature. All gas samples are reported as $\delta^{34} \mathrm{~S}_{\mathrm{V}-\mathrm{CDT}}$ of total sulfur. Samples for Cerro Negro include 3 gas samples collected by Elkins et al. (2006) in 2002 as well as two gas and two scoria samples collected in 2009 (de Moor, 2013). New $\delta^{34} S$ data are reported for a high temperature gas sample from Momotombo collected by Elkins et al. (2006) in 2002. Menyailov et al. (1986) presented S isotope data for fumaroles from Momotombo, and 3 high T samples are included in Table 1. Masaya plume and scoria samples were collected in 2009 and $S$ isotope data were previously reported in de Moor et al. (2013). One $\delta^{34} S$ value is available from Mather et al. (2006a) for Pele's hair collected at the crater rim. Gas data for Poás volcano include three moderate to high $\mathrm{T}$ gas samples collected by Erick Fernandez (OVSICORI-UNA) in 2008 and 2009, and 4 Giggenbach and bubbler samples collected for this study from fumaroles in 2013. The $S$ isotope composition of basaltic andesite erupted from Poás in 1953-1954 is reproduced from Rowe (1994). Sulfur isotope data for Turrialba plume and fumarole gases include 10 plume samples previously reported in de Moor et al., 2016b and 5 Giggenbach samples collected in 2006-2008 by Erick Fernández (OVSICORI-UNA).

The sulfur isotope compositions of volcanic gases from Nicaragua and Costa Rica are all positive, ranging between $+0.2 \%$ and $+6.8 \%$ o with lowest values measured at Turrialba and the highest at Momotombo. Considering only samples collected from sources with $\mathrm{T}$ above $450{ }^{\circ} \mathrm{C}$ reduces the potential for isotopic modification by shallow fumarolic processes such as native S deposition (Giggenbach, 1996; Aiuppa et al., 2014; Henley and Fischer, 2021) and removes some outliers from the data (Fig. 2). Heavier S isotope compositions are observed in gases from Nicaragua, which considered together give an average of $+4.8 \pm 1.4 \%$, with the highest average value of $+6.0 \pm 1.2 \%$ observed at Momotombo (average outlet temperature of $688^{\circ} \mathrm{C}$ ). The mean $\mathrm{S}$ isotope composition of high T volcanic gases from Costa Rica is $+2.3 \pm$ $1.3 \%$, with the lowest value observed at Poás volcano (average $+1.5 \pm$ $0.8 \%$ for high $\mathrm{T}$ samples). The most variation is observed at Turrialba volcano, where filtering the data for temperature decreases the variability about the mean significantly, from $\pm 1.7 \%$ for all samples to $\pm 0.5 \%$ if only high $\mathrm{T}$ samples are considered, without significantly changing the mean, from $+3.3 \%$ (all samples) to +3.1 (high $\mathrm{T}$ samples). Cerro Negro is the only volcano for which we cannot filter out lower $\mathrm{T}$ samples, as the sampling temperatures ranged from $310{ }^{\circ} \mathrm{C}$ to $98{ }^{\circ} \mathrm{C}$. However, we still consider the $S$ isotope composition $(+3.5 \pm 1.4 \%$ ) in further discussion for lack of high $\mathrm{T}$ samples and for completeness in considering along-arc trends. The average value considering all the SCAVA volcanoes is $+3.8 \pm 1.7 \%$ o (excluding Cerro Negro changes the average from +3.78 to $+3.84 \%$, making negligible difference). Along arc variation in gas $\delta^{34} \mathrm{~S}$ is observed (Fig. 3a), with heavier values in Nicaragua (average of $+4.8 \pm 1.4 \%$ ) compared to Costa Rica (average of $+2.3 \pm 1.3 \%$ ).

Few $\delta^{34} S$ data are available for scoria from SCAVA and those that are available present consistently heavy values relative to high $\mathrm{T}$ gases. Two basaltic scoria samples from Cerro Negro give values of $+9.3 \%$ and + $6.0 \%$ (de Moor, 2013) and those from Masaya yield an average of +7.3 $\pm 0.6 \%$ (de Moor et al., 2013; Mather et al., 2006b. One basaltic andesite sample from the 1952-1953 eruption of Poás volcano gave a 
Table 1

Sulfur isotope compositions of SCAVA gases and scoria listed by volcano from north to south.

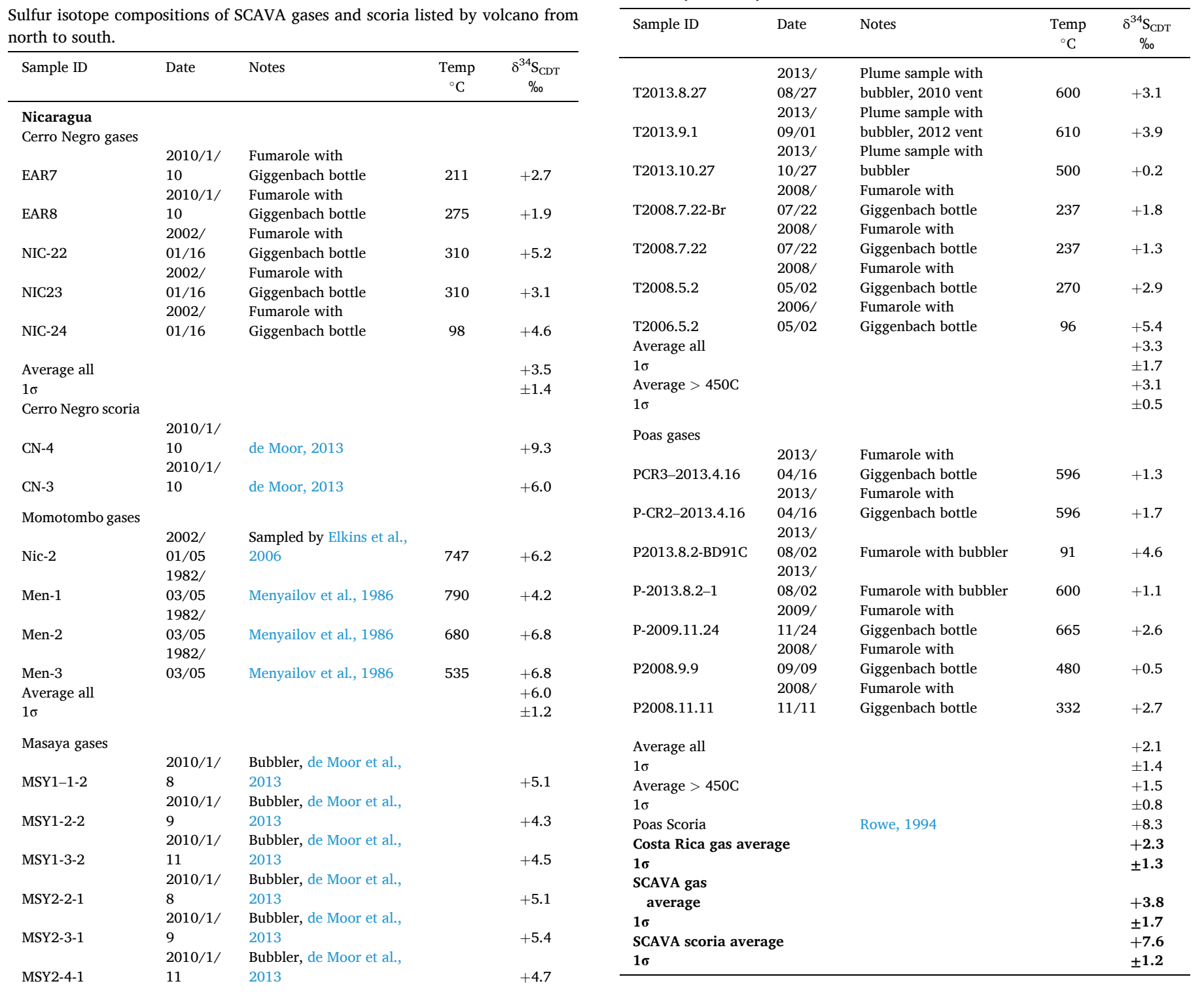

Average all

$1 \sigma$

Scoria

MAS-1

2010/1/ Modern rim scoria, de $8 \quad$ Moor et al, 2013 2010/1/ Modern rim scoria, de

MAS-1 glass sep $8 \quad$ Moor et al., 2013

Pele's hair

Nicaragua gas average

$1 \sigma$

Costa Rica

Turrialba gases

\begin{tabular}{|c|c|c|}
\hline \multirow{3}{*}{ T2013.4.13b } & 2013/ & Plume sample with \\
\hline & $04 / 13$ & bubbler, 2012 vent \\
\hline & 2013/ & Plume sample with \\
\hline \multirow[t]{2}{*}{ T2013.4.13a } & $04 / 13$ & bubbler, 2012 vent \\
\hline & 2013/ & Plume sample with \\
\hline \multirow[t]{2}{*}{ T2013.6.19 } & $06 / 19$ & bubbler, 2010 vent \\
\hline & 2013/ & Plume sample with \\
\hline \multirow[t]{2}{*}{ T-2013.7.19 } & $07 / 19$ & bubbler, 2010 vent \\
\hline & 2013/ & Plume sample with \\
\hline \multirow[t]{2}{*}{ T2013.8.8-B12b } & 08/08 & bubbler, 2012 vent \\
\hline & 2013/ & Plume sample with \\
\hline \multirow[t]{2}{*}{ T2013.8.8-B12a } & 08/08 & bubbler, 2012 vent \\
\hline & 2013/ & Plume sample with \\
\hline$\lceil 2013.8 .8$ & $08 / 08$ & bubbler, 2010 vent \\
\hline
\end{tabular}

Table 1 (continued)

value of $+8.3 \%$ (Rowe, 1994). The average value of SCAVA scoria is $+7.6 \pm 1.2 \%$, which is significantly heavier than the average SCAVA high temperature gas $\mathrm{S}$ isotope composition.

\section{Discussion}

\subsection{Correlations with other geochemical tracers}

Fig. 3 compares the average $\delta^{34} S$ of gas samples for SCAVA volcanoes (Table 1; Fig. 2) to published mean values for key tracers of deep magma sources (Elkins et al., 2006; Zimmer et al., 2004; Shaw et al., 2003; Hilton et al., 2010; Aiuppa et al., 2014; Carr et al., 2014 and references therein). The correlation with gas tracers is generally better than tracers from rock geochemistry, even though most of the $\delta^{34} \mathrm{~S}$ data were not collected on the same gas samples for which $\delta^{15} \mathrm{~N}, \delta^{13} \mathrm{C}$, and $\mathrm{CO}_{2} / \mathrm{S}_{\mathrm{T}}$ data were obtained. $\delta^{34} \mathrm{~S}$ correlates closely with $\delta^{15} \mathrm{~N}\left(\mathrm{R}^{2}=0.98\right.$, Fig. $\left.3 \mathrm{~b}\right)$, $\delta^{13} \mathrm{C}\left(\mathrm{R}^{2}=0.82\right.$, Fig. $\left.3 \mathrm{c}\right)$ and $\mathrm{CO}_{2} / \mathrm{S}_{\mathrm{T}}\left(\mathrm{R}^{2}=0.94\right.$ excluding Cerro Negro, Fig. 3d). Correlations with $\mathrm{U} / \mathrm{Th}$ and $\mathrm{Ba} / \mathrm{La}$ are less robust (Fig. 3e and f; $\left.\mathrm{R}^{2}<0.6\right)$ but positive trends are maintained.

The correlations between $\delta^{34} S$ and key geochemical parameters indicate that the sulfur isotope variations are controlled by primary volatile sources at SCAVA, namely mixtures between mantle volatiles 
and fluids derived from the subducted slab. Given these correlations, crustal contributions to the SCAVA sulfur output budget are negligible . Poás volcano represents an endmember dominated by mantle sulfur sources with little influence from slab-derived fluids, further supported by low $\delta^{15} \mathrm{~N}, \mathrm{CO}_{2} / \mathrm{S}_{\mathrm{T}}, \mathrm{U} / \mathrm{Th}$ and $\mathrm{Ba} / \mathrm{La}$. Masaya and Momotombo volcanoes represent a more typical arc endmember with $\delta^{34} \mathrm{~S}$ values of $+4.8 \%$ and $+6.0 \%$, respectively, high $\delta^{15} \mathrm{~N}, \mathrm{CO}_{2} / \mathrm{S}_{\mathrm{T}}$, U/Th and Ba/La. The relationship between $\delta^{34} \mathrm{~S}$ and $\delta^{15} \mathrm{~N}$ (Fig. 3b) is consistent with mixing between a mantle fluid endmember with $\delta^{15} \mathrm{~N} \sim-5 \%$ and slightly positive $\delta^{34} \mathrm{~S}$ (consistent with a mantle endmember similar to MORB; Sakai et al., 1984; Labidi et al., 2012) and a slab fluid endmember with $\delta^{15} \mathrm{~N}>+7 \%$ and $\delta^{34} \mathrm{~S}>+6.5 \%$. The correlation between $\mathrm{S}$ and $\mathrm{C}$ isotope compositions is consistent with mixing between a mantle endemember $\delta^{13} \mathrm{C} \sim-6 \%$ and slightly negative $\delta^{34} \mathrm{~S}$ (also within the range of MORB; Sakai et al., 1984; Labidi et al., 2012) and a slab fluid heavy endmember with $\delta^{13} \mathrm{C} \sim 0 \%$ and $\delta^{34} \mathrm{~S} \sim+8 \%$. For the purposes of further discussion, we therefore assign a mantle endmember with $\delta^{34} S$ $=0 \%$ and model the $S$ cycle as a function of the $S$ isotope composition of slab fluids, considering $+8 \%$ as a candidate composition supported by correlations with $\mathrm{C}$ and $\mathrm{N}$ isotopes, noting that the $\delta^{34} \mathrm{~S}$ value of slab fluids could be heavier (Alt et al. $(1993,2012$ ) have proposed $+8 \%$ to $+14 \%$ as slab fluid compositions).

\subsection{Model of $S$ outputs and inputs to SCAVA}

Sulfur mass balance through the subduction zone is conducted using a series of Monte Carlo calculations to assess uncertainties, considering bulk outputs (S isotope compositions and $\mathrm{S}$ mass fluxes) from the volcanic arc and bulk arc inputs at the trench (S isotope compositions and fluxes). Outputs considered are volcanic gases, degassed erupted volcanic rocks, and partially degassed intrusive igneous bodies (which feed hydrothermal systems). Subduction inputs at the trench consist of marine sediments, altered igneous oceanic crust (AIC), primary igneous crust (PIC), serpentinized mantle lithosphere, and subduction erosion.

Inputs to Monte Carlo calculations are assigned mean and $1 \sigma$ values (1 standard deviation) based on data presented in this work, values for components measured on the Cocos plate, and in cases where no specific data exist for the SCAVA margin reasonable mean and $1 \sigma$ values were assigned based on global datasets. Each step in the Monte Carlo simulations involved 10,000 iterations of the calculation considering a random distribution based on $1 \sigma$ about the mean of the assigned value. Uncertainties in resulting values are derived by taking $1 \sigma$ of the 10,000 results of the calculation in question. Details of chosen values for outputs and inputs are given in sections 3.2.1 to 3.3.5. Fig. 4 shows a representation of the robustness of the values introduced into the models, with the size of the squares proportional to the total fluxes represented by each input or output component. Blue colored squares indicate fluxes that we consider well constrained in terms of $S$ isotope composition and flux for SCAVA (gas output, AIC and PIC input). Orange squares show fluxes that we consider moderately constrained based on SCAVA specific data (output of erupted volcanic rocks and input by forearc erosion). Red squares show fluxes that we consider under-constrained (S output from partially degassed intrusions, $\mathrm{S}$ input from sediments, and $\mathrm{S}$ input from serpentinized mantle lithosphere).

Overall, the robustness of mass balance modeling depends on the robustness of model inputs and outputs and their relative contributions to mass balance through the subduction system. As shown in Fig. 4, the largest contributor to arc outputs (gas) is well constrained (data from this study) and the largest contributors to arc inputs (AIC and PIC) are also well constrained.

\subsection{1. $\mathrm{SO}_{2}$ gas fluxes}

Arc outputs include gases, erupted volcanic rocks, intruded magmas, and hydrothermal fluids. The SCAVA segment is perhaps, after Japan (Mori et al., 2013; Shinohara, 2013), the best-characterized in the world in terms of volcanic $\mathrm{SO}_{2}$ emissions (Stoiber et al., 1987; Andres and
Kasgnoc, 1998; Mather et al., 2006b; Aiuppa et al., 2014; de Moor et al., 2017). In order to constrain the total S output from SCAVA we consider the period from 1997 to 2017, which is robustly characterized in terms of $\mathrm{SO}_{2}$ flux measurements.

Andres and Kasgnoc (1998), Mather et al. (2006b), and Aiuppa et al., 2014 reported $\mathrm{SO}_{2}$ fluxes for the Costa Rica - Nicaragua arc segment of $2147 \mathrm{~T} / \mathrm{d}, 2031 \pm 711 \mathrm{~T} / \mathrm{d}$, and $1886 \pm 495 \mathrm{~T} / \mathrm{d}$, respectively, which we accept as robust estimates of the arc gas output for the period 1997-2014. de Moor et al. (2017) reported higher $\mathrm{SO}_{2}$ fluxes for the period 2014-2017 of $6240 \pm 1150 \mathrm{~T} / \mathrm{d}$, attributed to a regional increase in volcanic activity perhaps associated with extension in the upper plate following the Mw 7.6 Nicoya and Mw 7.3 El Salvador earthquakes in 2012. For the purposes of mass balance modeling, the total mass of $\mathrm{SO}_{2}$ emitted from the arc during the period 1997-2017 is taken as the weighted average of $9688 \pm 4844 \mathrm{kT}$ (assuming an uncertainty of 50\%, which is greater than measurement errors) or $1.44 \pm 0.72 \times 10^{10} \mathrm{mols}$ / yr $\mathrm{SO}_{2}$. The contributions from the Nicaraguan and Costa Rican segments are $0.93 \pm 0.47 \times 10^{10} \mathrm{mols} / \mathrm{yr} \mathrm{SO}_{2}$ and $0.51 \pm 0.26 \times 10^{10} \mathrm{mols} /$ yr $\mathrm{SO}_{2}$, respectively.

\subsubsection{S output as erupted and non-erupted magmas}

The amount of $S$ emitted from SCAVA in terms of that contained in erupted rock is derived from the long-term magma eruption rate. Kutterolf et al. (2008) calculated magma eruption rates for all the volcanoes constructing the Central American Volcanic Arc. Based on these estimates, we calculate that the total magma eruptive rate for SCAVA per arc length at $1.27 \mathrm{~g} / \mathrm{s} / \mathrm{m}(1.61 \mathrm{~g} / \mathrm{s} / \mathrm{m}$ for Nicaragua and $0.79 \mathrm{~g} / \mathrm{s} / \mathrm{m}$ for Costa Rica). For comparison, we also calculated the eruptive rate for 1997-2017 based on the number and magnitude of eruptions that occurred during this time. During this period there were 51 VEI 1 eruptions at SCAVA (16 in Costa Rica and 35 in Nicaragua) and 44 VEI 2 eruptions (25 in Costa Rica and 19 in Nicaragua) (GlobalVolcanismProgram, 2013). We estimate the total volume of erupted material considering that, by definition, VEI 1 eruptions produce $10^{4}-10^{6} \mathrm{~m}^{3}$ of material and VEI 2 eruptions produce $10^{6}-10^{7} \mathrm{~m}^{3}$ of material. For the purposes of the magma volume calculation we assume that VEI 1 eruptions produce $5.1 \pm 3.4 \times 10^{5} \mathrm{~m}^{3}$ of material and VEI 2 eruptions produce $5.5 \pm 3.7 \times 10^{6} \mathrm{~m}^{3}$ of material, values which represent the midpoints between the volumes defined by the VEI scale (with uncertainties of $67 \%$ ). Assuming that these deposits, which are dominantly ashes and scoria, have a dry bulk density of $1500 \pm 500 \mathrm{~kg} / \mathrm{m}^{3}$ we calculate an eruptive rock output for SCAVA of $1.12 \pm 0.84 \mathrm{~g} / \mathrm{s} / \mathrm{m}$ (uncertainty from Monte Carlo method), which is in agreement with the estimate based on Kutterolf et al. (2008). For the purposes of mass balance modeling we favor the long-term eruptive output because this allows further constraints on non-erupted magma emplacement rate (see below). Considering that the S content of scoria erupted at SCAVA is typically $100 \pm 50$ ppm (e.g. Wade et al., 2006; de Moor et al., 2013; de Moor et al., 2016b), we calculate the $\mathrm{S}$ output flux as erupted magma is $6.57 \pm 3.29 \times 10^{7} \mathrm{mols} / \mathrm{yr} \mathrm{S}\left(4.89 \pm 2.44 \times 10^{7} \mathrm{mols} / \mathrm{yr} \mathrm{S}\right.$ for Nicaragua and $1.69 \pm 2.44 \times 10^{7}$ for Costa Rica).

Kutterolf et al. (2008) further calculated the total magma flux (intrusive plus extrusive) for SCAVA accounting for magmatic differentiation and associated cumulate masses using incompatible element variations. Subtracting the extrusive component from these estimates we derive an intrusive magma emplacement flux for SCAVA of $1.37 \mathrm{~g} / \mathrm{s}$ / $\mathrm{m}(1.77 \mathrm{~g} / \mathrm{s} / \mathrm{m}$ for Nicaragua and $0.81 \mathrm{~g} / \mathrm{s} / \mathrm{m}$ for Costa Rica). Intruded magma would not degas as efficiently as erupted magma and would contain significantly more $S$ than erupted magma. The sulfur content of emplaced magmas will vary greatly depending on the depth of emplacement and extent of $S$ degassing and at any given point in time there will be magmas in the crust at varying stages of degassing. The average $S$ content of olivine- and clinopyroxene-hosted melt inclusions volcanoes at SCAVA ranges from $>3000 \mathrm{ppm}$ to $<200 \mathrm{ppm}$ (average of 989 ppm considering data from Roggensack et al., 1997; Wallace, 2005; Wade et al., 2006; Benjamin et al., 2007; de Moor et al., 2013; de Moor 
et al., 2016b; Robidoux et al., 2017a; Robidoux et al., 2017b). For the purposes of calculating the $S$ flux associated with these partially degassed magmas, we assume a $S$ content of $1000 \pm 500 \mathrm{ppm}$, which yields a S flux of $7.10 \pm 3.55 \times 10^{8} \mathrm{mols} / \mathrm{yr}$ for SCAVA $(5.37 \pm 2.68 \times$ $10^{8} \mathrm{mols} / \mathrm{yr}$ for Nicaragua and $1.73 \pm 0.87 \times 10^{8} \mathrm{mols} / \mathrm{yr}$ for Costa Rica). Further crystallization of these stalled magmas in the crust releases $\mathrm{S}$ to deep hydrothermal systems and results in sulfide/sulfate mineral sequestration and minor $\mathrm{H}_{2} \mathrm{~S}$ emissions at the surface. Thus, our mass balance model considers both hydrothermal fluxes and mineral sequestration by assuming that these fluxes are ultimately linked to the magma production rate.

\subsubsection{Excess $S$ on the arc scale}

Table 2 compares the $S$ output fluxes from gas, erupted magma, and non-erupted magma, showing that the total S output from SCAVA is $1.52 \pm 0.42 \times 10^{10} \mathrm{~mol} / \mathrm{yr}$ and that $95 \%$ of the output is in the form of gas. The total amount of $\mathrm{S}$ emitted as $\mathrm{SO}_{2}$ gas is $\sim 200$ times that emitted in erupted rocks, and a factor of $\sim 20$ more than that from partially degassed intrusions.

A commonly recognized phenomenon, "excess sulfur" was first recognized at Fuego volcano by Rose et al. (1982), where the amount of $\mathrm{SO}_{2}$ released from erupting volcanoes is greater than can be accounted for by the mass of erupted magma. Excess sulfur has been observed at many volcanoes world-wide, is more apparent at arc volcanoes, and has been attributed to gas-melt separation at mid to shallow crustal levels in magmatic plumbing systems (e.g. Wallace, 2005; Shinohara, 2008; de Moor et al., 2010) .

Our S output estimates for SCAVA highlight that excess S emissions also occur on the regional scale and not only for individual eruptions. If we consider the total magma production rate for SCAVA $(1,387,345 \mathrm{~g} / \mathrm{s}$; Kutterolf et al., 2008) and an average undegassed S content of $2850 \mathrm{ppm}$ from olivine-hosted melt inclusions (Roggensack et al., 1997; Wallace, 2005; Wade et al., 2006; Benjamin et al., 2007; de Moor et al., 2013; de Moor et al., 2016b; Robidoux et al., 2017a, 2017b) then the magma production rate could account for $3.9 \times 10^{9} \mathrm{mols} / \mathrm{yr}$ of $\mathrm{SO}_{2}$ if all of the dissolved $\mathrm{S}$ was efficiently degassed. This petrologically derived $\mathrm{SO}_{2}$ flux is a factor of 3.7 lower than the observed $\mathrm{SO}_{2}$ flux from SCAVA (1.44 \pm $0.72 \times 10^{10} \mathrm{mols} / \mathrm{yr} \mathrm{SO}$ ). Even if we assign an initial (undegassed) $\mathrm{S}$ content of $5000 \mathrm{ppm}$ (i.e. higher than the maximum $\mathrm{S}$ solubility at $4 \mathrm{kbars}$ and oxygen fugacity of $\mathrm{NNO}+4$; Wallace, 2005), to the total magma production rate (i.e. intrusive + extrusive magma output), the total $\mathrm{SO}_{2}$ flux is still a factor of 2 greater than what could be accounted for by magmas. This observation suggests that some of the $\mathrm{S}$ emitted from the arc could originate as a free fluid phase independent of silicate melts or that the initial S content of primary arc magmas is significantly underestimated.

\subsubsection{Sulfur isotope composition of total arc outputs}

The mean $\mathrm{S}$ isotope composition of high temperature SCAVA gases is $+3.8 \pm 1.7 \%$. Sulfur isotope data are available for a limited number erupted scoria samples from Poás, Masaya, and Cerro Negro (Rowe, 1994; Mather et al., 2006a; de Moor et al., 2013; de Moor, 2013), yielding an average value of $+7.6 \pm 1.2 \%$, which is heavier than the average value observed in gases. The $S$ isotope composition of partially degassed unerupted magmas is poorly constrained; however, the $\delta^{34} S$ value of this $S$ must lie somewhere between that of the gas phase and

Table 2

Sulfur fluxes and isotope compositions for SCAVA outputs.

\begin{tabular}{|c|c|c|c|c|}
\hline & S Flux & \pm & $\delta^{34} \mathrm{~S}$ & \pm \\
\hline & $\mathrm{mol} / \mathrm{yr}$ & $\mathrm{mol} / \mathrm{yr}$ & $\%$ & $\%$ \\
\hline Gas & $1.44 \times 10^{10}$ & $7.21 \times 10^{9}$ & +3.8 & 1.7 \\
\hline Erupted magma & $6.57 \times 10^{7}$ & $3.29 \times 10^{7}$ & +7.6 & 1.2 \\
\hline Non-erupted magma & $7.10 \times 10^{8}$ & $3.55 \times 10^{8}$ & +5.1 & 2.0 \\
\hline SCAVA total output & $1.52 \times 10^{10}$ & $4.17 \times 10^{9}$ & +3.9 & 1.0 \\
\hline
\end{tabular}

residual $\mathrm{S}$ in erupted magma (scoria). Therefore, we assume that unerupted and partially degassed magma has $\delta^{34} \mathrm{~S}=+5.1 \%$ (assuming $50 \%$ degassing; Fig. 4) and assign a large uncertainty of $\pm 2 \%$ to this value as it is not based on direct measurements but is rather an assumed value based on $\mathrm{S}$ degassing fractionation modeling (next section). As shown in Table 2, the bulk $\mathrm{S}$ isotope composition of arc outputs from SCAVA is calculated at $+3.9 \pm 1.0 \%$, which is the average $\delta^{34} S$ of gas, erupted magma, and non-erupted magma weighted according to their relative contributions to the total S output from the arc, with the uncertainty derived from the Monte Carlo error calculations.

\subsubsection{Sulfur degassing fractionation}

The distribution of the $S$ isotope compositions of SCAVA arc outputs (Table 2) can be described by isotopic fractionation produced by the degassing process. Fig. 5 shows degassing fractionation models following de Moor et al. (2013) together with the isotope compositions of SCAVA arc outputs. Degassing is modeled as an open system process (Rayleigh fractionation; Holloway and Blank, 1994) where the sampled gas phase (point $\mathrm{G}$ ) is considered an accumulation of gas derived from steady-state degassing of magma conduit (see de Moor et al. (2013) for equations and model details).

In Fig. 5, the isotopic composition of gas is plotted at an X-axis value of $95 \%$, consistent with the proportion of total arc output attributed to gas emissions. The isotopic composition of erupted magma (i.e. residual melt after extensive $\mathrm{S}$ loss to the gas phase) is plotted at an $\mathrm{X}$-axis value of $90 \%$ (i.e. $90 \%$ of melts initial $S$ lost to the gas phase), which is consistent with studies of melt inclusions and matrix glasses for SCAVA volcanoes ( $<3000 \mathrm{ppm}$ in melt inclusions, $<300 \mathrm{ppm}$ in matrix glass). The assumed isotopic composition of non-erupted magma (assumed to be $50 \%$ degassed; point NM in Fig. 5) is estimated based on the degassing fractionation model using $\alpha_{\text {gas-melt }}=0.9985$ under the opensystem conditions that best describe the observed average compositions of gas and erupted magma (i.e. scoria) at SCAVA.

The calculated isotopic composition of the total SCAVA output $(+3.9$ $\pm 1.0 \%$; Table 2) is plotted at an $\mathrm{X}$-axis value of $0 \%$ (point $\mathrm{T}$ in Fig. 5 ), reflecting the assertion that if all the magmatic $S$ outputs from the arc are constrained then the calculated total $S$ flux is equivalent to the total steady state magmatic $S$ flux before any degassing phase separation. In the degassing fractionation model, the y-intercept of the modeled melt curves $\left(\delta^{34} S=+4 \%\right.$ ) therefore reflects the isotopic composition of primary melts before any degassing fractionation occurred. Our calculated $\delta^{34} S$ value for total SCAVA outputs is essentially identical to the modeled composition of primary arc melts.

The best fit model to account for the isotopic compositions of gas and erupted magma is obtained with using $\alpha_{\text {gas-melt }}=0.9985$ and open system conditions. This $\alpha$ value can be reproduced with equilibrium magma degassing conditions with $T=1000{ }^{\circ} \mathrm{C}, \mathrm{S}$ in the melt existing predominantly as $\mathrm{S}^{6+}\left(\mathrm{S}^{6+} /\left(\mathrm{S}^{6+}+\mathrm{S}^{2+}\right)=0.9\right)$, and a gas phase dominated by $\mathrm{SO}_{2}\left(\mathrm{SO}_{2} /\left(\mathrm{SO}_{2}+\mathrm{H}_{2} \mathrm{~S}\right)=0.9\right)$. These characteristics are consistent with degassing of typical oxidized arc basaltic-andesite melts (e.g. de Moor et al., 2013).

It is important to note that the models do not provide a unique solution with regards to the initial isotope composition of primary arc melts, nor for the magma degassing conditions. The model presented in Fig. 5 does nevertheless serve to demonstrate that the isotopic values for gas, erupted magma, non-erupted magma, and total SCAVA output (Table 2) are consistent with isotopic fractionation during magma degassing. We note however that the isotope composition of erupted magma is poorly constrained because few $\delta^{34} S$ data are available for scoria, which were not erupted at the same time as gas samples. Future work should aim to improve understanding of gas-melt fractionation by detailed analysis of scoria and melt inclusion $S$ isotope compositions using updated S extraction methods (Labidi et al., 2012) and secondary ion mass spectrometry (Taracsák et al., 2021). Note however that our estimate of the $S$ isotope composition of total arc output is not sensitive to changes in the estimated $\delta^{34} \mathrm{~S}$ of erupted magma because the 
contribution of S output as erupted magma to the total output budget is minor (Table 2, Fig. 4).

\subsection{Arc inputs}

Here we aim to constrain the total flux of S into the SCAVA subduction zone as well as its bulk $S$ isotope composition and speciation in order to conduct mass balance modeling of $S$ recycling through the arc. Two primary controls on the subduction inputs are the crustal thickness of the subducting slab and the convergence rate. Oceanic crust formed at the East Pacific Rise (EPR) is thinner, older, and smoother than that formed at the Cocos-Nazca Spreading Center (CNS; Fig. 1, Fig. 6; e.g. Van Avendonk et al., 2011). Walther et al. (2000) determined that the thickness of the oceanic plate off Nicaragua is $5.5 \mathrm{~km}$ with an uncertainty of 1-2 km. For the purposes of mass balance modeling we assign an uncertainty of $33 \%$ to the EPR crustal thickness (5500 $\pm 1830 \mathrm{~m})$. In contrast, the oceanic crust subducted in Costa Rica is significantly thickened due to interaction with the Galapagos hotspot (Walther, 2003). Based on the wide-angle seismic experiments of Walther (2003) we estimate that the oceanic crust currently subducting in the direction of Poás and Turrialba volcanoes has a total thickness of $8500 \pm 3140 \mathrm{~m}$. The convergence rate at SCAVA is $75.7 \pm 2.7 \mathrm{~km} / \mathrm{ma}$ at a convergence angle of $22^{\circ}$ and does not vary significantly along strike (Syracuse and Abers, 2006).

The sulfur concentrations, isotope compositions, and S speciation of oceanic crust are highly heterogeneous (Fig. 7) within and between subducted lithologies, containing oxidized and isotopically heavy minerals such as gypsum and barite (sulfates, $\mathrm{S}^{6+}$ ) as well as more reduced and isotopically lighter $S$ in the form of pyrite $\left(S^{1-}\right)$ and pyrrhotite $\left(S^{2-}\right)$.
Cerro Negro

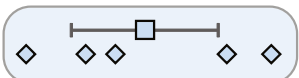

Momotombo

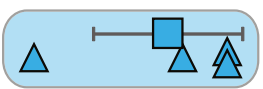

Masaya

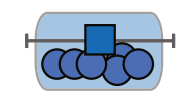

Poás

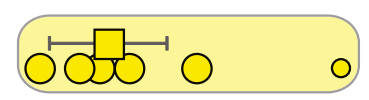

Turrialba
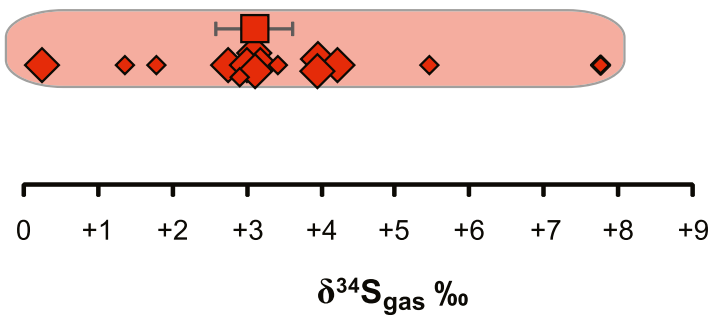

Fig. 2. Sulfur isotope compositions of gases from SCAVA volcanoes. Individual samples are shown (smaller symbols are samples of gas with $T<450{ }^{\circ} \mathrm{C}$, larger symbols are samples of gas with $T>450{ }^{\circ} \mathrm{C}$ ). The shaded boxes show the range and the squares with error bars show the mean and standard deviation for each volcano.

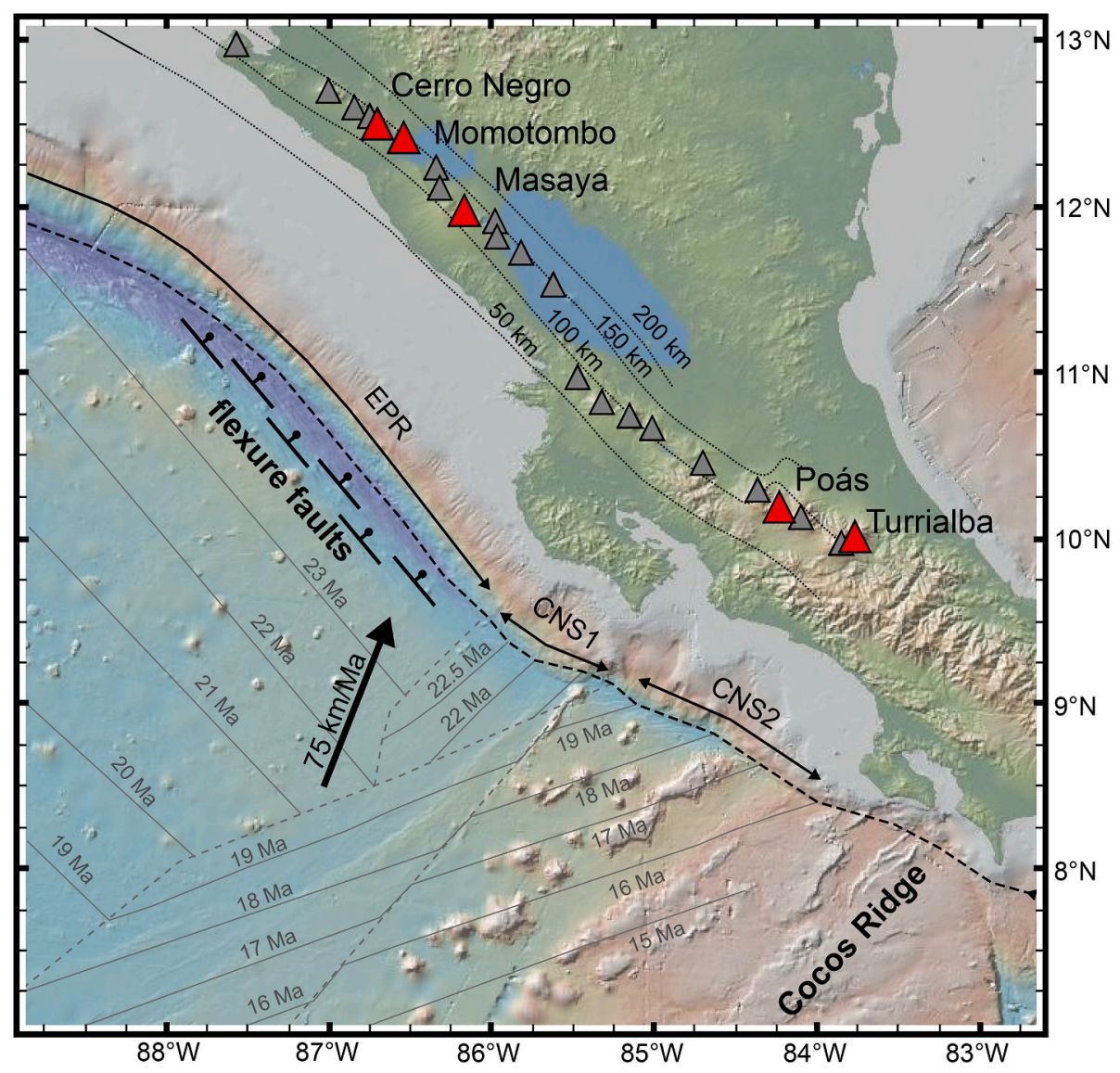

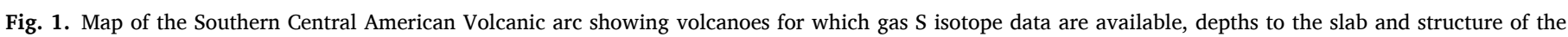

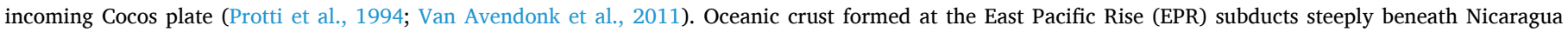
whereas crust formed at the Cocos Nazca Spreading Center (CNS) subducts beneath Costa Rica at a shallow angle due to the rigidity of the Cocos Ridge. 

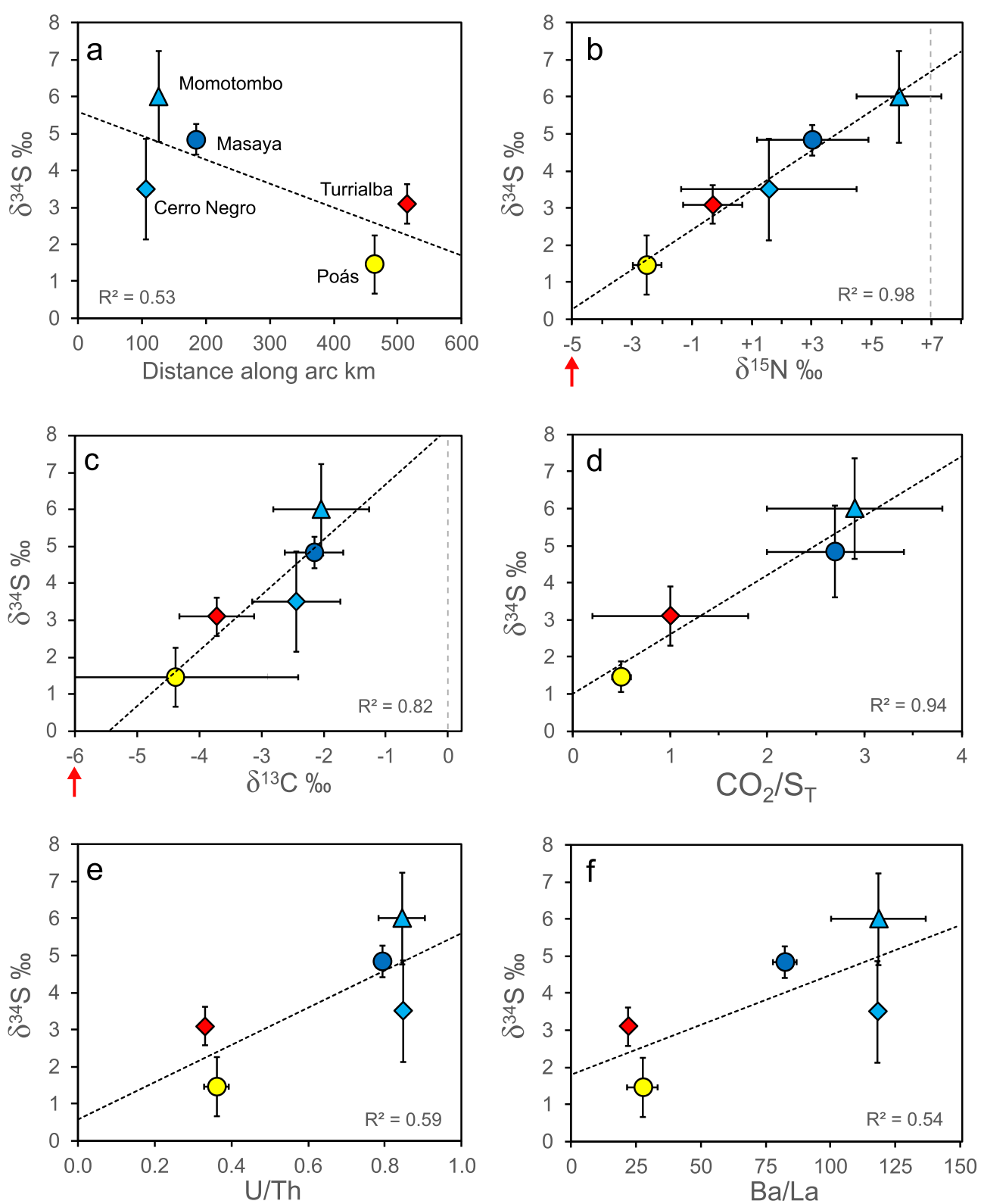

Fig. 3. Correlation plots between $S$ isotope compositions of SCAVA gases and a) distance along arc, b) gas nitrogen isotope compositions (Elkins et al., 2006; Zimmer et al., 2004), c) gas carbon isotope compositions (Shaw et al., 2003; Hilton et al., 2010), d) gas $\mathrm{CO}_{2}$ over total S ratio (Aiuppa et al., 2014), e) rock U/Th (Carr et al., 2014 and references therein), and f) rock Ba/La (Carr et al., 2014 and references therein). Red arrows indicate mantle volatile endmembers. Vertical dashed grey lines in $\mathrm{b}$ and $\mathrm{c}$ show isotopically heavy endmembers (sedimentary $\mathrm{N}$ and limestone $\mathrm{C}$, respectively) commonly used to explain heavy $\delta^{15} \mathrm{~N}$ and $\delta^{13} \mathrm{C}$ observed in arc gas emissions (e.g. Fischer et al., 2002; Shaw et al., 2003). (For interpretation of the references to colour in this figure legend, the reader is referred to the web version of this article.)
The characteristics of subducted lithologies with respect to $S$ for EPR and CNS crust are summarized in Table 3. The values used for the various lithological packages in our model of subducted $S$ inputs are discussed in detail in the Supplementary Information and summarized in brief below.

\subsubsection{Subducted marine sediments}

Marine sediments on the Cocos plate consist of an upper unit of pyrite-bearing silty claystone and a lower unit of barite-bearing carbonate (Fig. 7). The thicknesses of these layers is constrained from holes 1039 for the EPR section and holes U1381 and U1414 for the CNS section (Fig. 6). In hole 1039 the upper unit has a thickness of $112 \mathrm{~m}$ and the lower unit has a thickness of $289 \mathrm{~m}$, which we assign uncertainties of $33 \%$. The thickness of sediments on the CNS crust is highly variable due to significant topography associated with the Cocos ridge flanks and seamounts. We take the average of thicknesses measured at holes U1381 and $\mathrm{U} 141(240 \mathrm{~m})$ and assume a $67 \%$ uncertainty for total CNS sediment thickness. We estimate that the upper $63 \%(151 \mathrm{~m})$ of the CNS section is pyrite bearing and the remaining $89 \mathrm{~m}$ lower is pyrite poor (Supplementary Information; Fig. 7).

The pyrite $S$ and barite $S$ content of the two sedimentary units is estimated based on total S concentrations measured by Kimura et al. (1997) and Ba concentrations measured by Solomon and Kastner (2012) (Supplementary Information), with the upper unit containing $7900 \pm$ $2700 \mathrm{ppm}$ pyrite $S$ and $100 \pm 40 \mathrm{ppm}$ barite $S$ and the lower unit containing $640 \pm 250 \mathrm{ppm}$ barite $S$ and no pyrite $S$. The sulfur isotope composition of sedimentary pyrite is here taken to be $-20 \pm 10 \%$ after Canfield (2004) and Alt and Burdett (1992) and the $\delta^{34} S$ of sedimentary sulfate is assumed to be that of seawater sulfate, $+21 \pm 5 \%$ (Kurtz et al., 2003).

The calculated bulk compositions of subducted sediments are summarized in Table 3 and are reported with Monte Carlo uncertainties. In our model, the $\mathrm{S}$ isotope composition of bulk CNS sediment is lighter than that of EPR $(-17.3 \%$ vs $-11.4 \%$ ) due to a thicker pyrite-bearing upper unit (Table 3, Fig. 7).

\subsubsection{Altered igneous crust}

Holes $1256 \mathrm{D}$ and 504B (Fig. 6) are used to quantify the $S$ inputs from EPR and CNS altered ocean crust (AIC), respectively. The S chemistry of AIC in these holes has been studied extensively (Alt et al., 1989; Alt, 1995a; Alt and Shanks, 2010; Alt and Shanks, 2011). Sublithologies of 


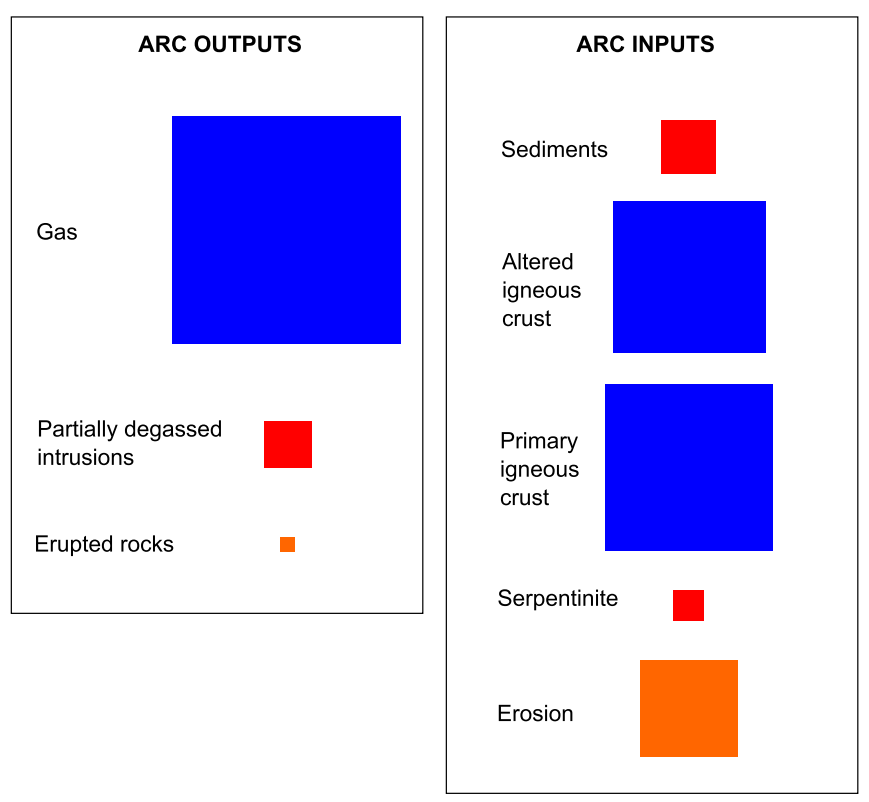

Fig. 4. Comparison between arc output and subduction input fluxes. The sizes of the colored boxes indicate the relative contribution of the component considered. Blue fill indicates that the flux is relatively well constrained with $S$ isotope data available for the SCAVA margin (gas output, AIC input) or that the isotope composition thereof is unlikely to vary significantly (PIC). Orange fill indicates that few relevant sulfur isotope data are available and/or the flux is poorly constrained and therefore the component is considered moderately constrained. Red fill indicates that no $S$ isotope data are available for that component in the SCAVA setting (i.e. sediments and partially degassed intrusions), or that the flux is poorly characterized (serpentinite). Overall, bulk S inputs are greater than total arc outputs at SCAVA by a factor of 1.3 (outer boxes). (For interpretation of the references to colour in this figure legend, the reader is referred to the web version of this article.)

the AIC are extrusive volcanics, transition zone breccia, sheeted dikes, and altered gabbro and the thicknesses thereof are estimated from Walther (2003), Walther et al. (2000), and Teagle et al. (2006) (Supplementary Information; Fig. 7). The CNS AIC is significantly thickened compared to the EPR AIC due to magmatism associated with Cocos Ridge and the Galapagos hotspot track (Walther, 2003). The dominant characteristics of alteration processes in the AIC are S loss from the extrusive volcanics, sulfide mineralization in the transition zone breccia, and pyrite and anhydrite veining in the altered dikes and altered gabbro (Alt et al., 2010; Alt and Shanks, 2011).

The S chemistry of the AIC sections for the EPR and CNS plates is detailed in the Supplementary Information and summarized in Table 3. The lower S concentration of CNS AIC $(630 \pm 60$ ppm versus $1490 \pm$ 190 ppm for the EPR AIC) is largely due to enhanced S loss associated with extensive off axis low temperature hydrothermal circulation, which is promoted by rough topography and the lack of a sedimentary seal on topographic highs (Alt et al., 2010; Alt and Shanks, 2010). The higher bulk $\delta^{34} S$ values of the EPR crust $(+3.0 \pm 1.6 \%$ versus $+0.9 \pm 0.4$ for the CNS AIC) is due to the more intense near-axis alteration and higher degrees of seawater sulfate fixation at fast spreading centers (Alt, 1995b; Alt et al., 2010; Alt and Shanks, 2010).

\subsubsection{Primary igneous crust}

The unaltered plutonic section of igneous oceanic crust contains primary MORB sulfides in the form of disseminated igneous pyrrhotite and is relatively homogeneous with respect to S compared to the other subducted lithologies (Alt et al., 1989; Alt and Anderson, 1991; Alt, 1995a). The isotope composition of bulk MORB was determined by Sakai et al. (1984) to vary between $-3.6 \%$ and $+2.2 \%$ (average + $0.3 \%$ ), whereas Labidi et al. (2012) reported values between -1.9 and $+0.2 \%$ (average $-0.9 \%$ ). Here we adopt the value of $+0.1 \pm 0.5 \%$ o from Alt (1995a) in our mass balance calculations, which is an intermediate value between the average MORB values reported by Sakai et al. (1984) and Labidi et al. (2012). The PIC is a major transporter of S into the subduction zone due to its extensive thickness ( $3400 \mathrm{~m}$ for the
EPR and $4400 \mathrm{~m}$ for the CNS; Supplementary Information; Fig. 7).

\subsubsection{Serpentinitized mantle lithosphere}

Serpentinized oceanic peridotite is recognized as an important component of subduction inputs for volatile cycling (Barnes et al., 2009; Rüpke et al., 2002; Stern et al., 2006; Alt et al., 2013; Freundt et al., 2014). Flexure faulting parallel to tectonic fabric (isochrons in Fig. 1) on the outer rise of the EPR plate results in more serpentinization of the mantle lithosphere in comparison to the more rigid CNS plate. Based on the studies of Grevemeyer et al. (2007), Van Avendonk et al. (2011), and Freundt et al. (2014), we adopt a $7 \mathrm{~km}$ thick upper mantle that is $20 \%$ serpentinized, equivalent to a layer of pure serpentinite $1400 \mathrm{~m}$ thick for the EPR plate, assuming a high uncertainty of $67 \%$. Serpentinization of the CNS mantle is poorly constrained but available evidence suggests minor serpentinization. Ye et al. (1996) for example observed mantle seismic velocities of $\sim 8.1 \mathrm{~km} / \mathrm{s}$ in trench perpendicular seismic refraction lines, implying negligible serpentinization of the CNS upper mantle. Van Avendonk et al. (2011) concluded that there is a factor of $\sim 2.5$ less serpentinization of the SE EPR upper mantle than the EPR upper mantle off Nicaragua, and likely even less serpentinization of the CNS upper mantle. Thus, for the CNS subducted slab we assume that the upper mantle contains a factor of 3 less serpentinite than the upper mantle subducted at Nicaragua.

For the S chemistry of subducted serpentinite we rely on the review and compilation of Alt et al. (2013; Supplementary Information). The bulk $S$ isotope composition adopted for serpentinites in our mass balance calculations is $+6.7 \pm 1.9 \%$, reflecting the isotopic composition observed in both high temperature and low temperature serpentinites (Supplementary Information). It is important to note that the majority of serpentinite subducted at the Central American trench is thought to form at the outer rise due to plate flexure, normal faulting, and seawater penetration to mantle depths just prior to subduction (e.g. Grevemeyer et al., 2007; Van Avendonk et al., 2011; Freundt et al., 2014). There are no samples of this material and the processes forming this serpentinite may not be directly analogous to sampled serpentinites of gabbroic 


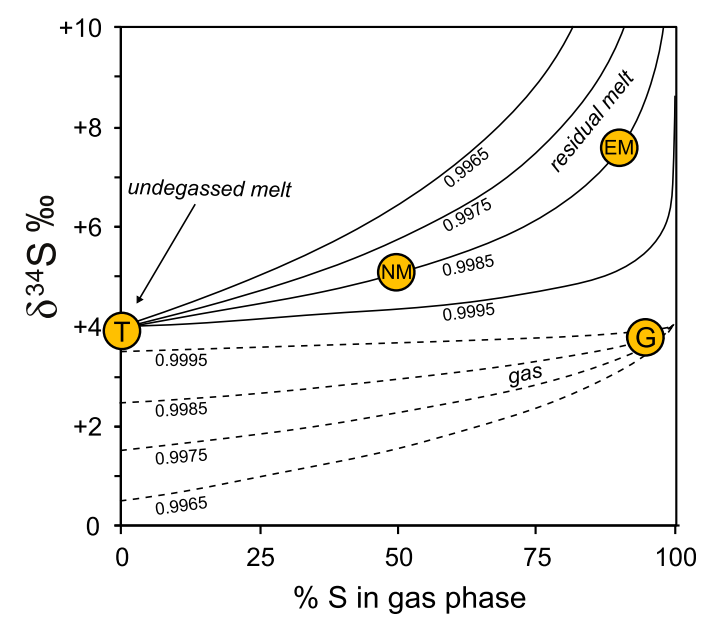

Fig. 5. Sulfur degassing fractionation models with isotopic compositions of SCAVA arc outputs (Table 2). Solid and dashed lines represent melt and gas Rayleigh fractionation curves, respectively, with the gas modeled as an accumulated phase. Curves are labeled with fractionation factor values $\left(\alpha_{\text {gas-melt }}\right)$. The isotopic compositions of SCAVA gas (point G) and erupted magma (point EM) can be adequately described by open system degassing, with $\alpha_{\text {gas-melt }}=$ 0.9985 where the initial isotopic composition of the undegassed melt is $+4 \%$. The isotopic composition adopted for non-erupted magma (i.e. partially degassed melt) in our mass balance model (Table 2) is shown as point NM.

hydrothermal systems or low T fault systems (Alt et al., 2013). Given this uncertainty, we consider the input flux of serpentinite as the least constrained component of our mass balance model (Fig. 4).

\subsubsection{Subduction erosion}

The erosion of material from the base of the upper plate is a significant contributor to the mass flux into subduction zones (e.g. Clift and Vannucchi, 2004). The composition of this entrained material will be similar to that of the forearc basement (Freundt et al., 2014). Vannucchi et al. (2001) showed that subduction at the Nicoya peninsula of Costa Rica erodes material from the forearc Nicoya complex, which is essentially altered oceanic crust. Walther et al. (2000) concluded that the forearc basement offshore Nicaragua is also accreted altered oceanic crust. Thus, following Freundt et al. (2014) we assume that the S content and $\mathrm{S}$ isotope composition of material introduced into the subduction zone by forearc erosion is that of AIC (Table 3).

Subduction erosion is less efficient in Nicaragua than in Costa Rica due to a smoother oceanic plate (Vannucchi et al., 2003). We adopt the Nicaraguan forearc erosion rate used by Freundt et al. (2014) of $30 \mathrm{~km}^{3}$ / $\mathrm{my} / \mathrm{km}$ (Supplementary Information). In terms of the stratigraphy of the subducted slab, this is equivalent to a thickness of $420 \mathrm{~m}$, which we assign an uncertainty of $50 \%$. The subduction erosion rate at the Costa Rican margin has been very high since the late Miocene (Vannucchi et al., 2003) and we adopt a value of $113 \mathrm{~km}^{3} / \mathrm{my} / \mathrm{km}( \pm 33 \%)$. Translated into equivalent stratigraphic thickness, this input equates to a $1520 \mathrm{~m}$ thick subducted layer for the CNS plate.

\subsubsection{Bulk $S$ inputs to the subduction zone}

The total calculated $S$ fluxes, isotope compositions, and $S$ speciation for the EPR and CNS segments are presented in Table 4 and Fig. 8 . The total S fluxes into SCAVA are estimated at $1.1 \pm 0.1 \times 10^{10} \mathrm{mols} / \mathrm{yr}$ and $0.9 \pm 0.1 \times 10^{10} \mathrm{mols} / \mathrm{yr}$ for the EPR and CNS segments respectively, for a total input of $2.0 \pm 0.1 \times 10^{10} \mathrm{mols} / \mathrm{yr}$ for the total input flux. The EPR and CNS total input fluxes are similar primarily due to tradeoffs between trench length (longer for the EPR segment) and total crustal thickness (thicker for the CNS section; Table 3). The thicker AIC section for the CNS segment is also associated with lower $\mathrm{S}$ concentrations compared to that of the EPR segment (Table 3), dampening the influence of the thickened AIC and enhanced subduction erosion at the Costa Rican margin.

The bulk S isotope composition of subduction input is $+0.7 \pm 0.4 \%$, with slightly higher values associated with the EPR total input $(+1.4 \pm$ $0.5 \%$ ) compared to CNS input $(-0.2 \pm 0.4 \%$ ). This difference is largely due to the influence of the AIC, which is a dominant carrier of $S$ into the subduction zone and has isotopically heavier values at the EPR (due to higher degrees of seawater sulfate fixation at fast spreading centers; Alt et al., 2010; Alt and Shanks, 2010) compared to the CNS (+3.0 $\pm 1.6 \%$ versus $+0.9 \pm 0.4 \%$ respectively). The other major transporter of heavy $\mathrm{S}$ in the EPR inputs is serpentinized mantle lithosphere, which has a factor of 4 higher flux compared to that of the CNS segment. The slightly negative $\delta^{34} \mathrm{~S}$ value associated with the bulk CNS input is due to the influence of subducted sediments, which is calculated at $-17.3 \pm 3.2 \%$ for CNS compared to $-11.4 \pm 3.0 \%$ for EPR. The pyrite-bearing

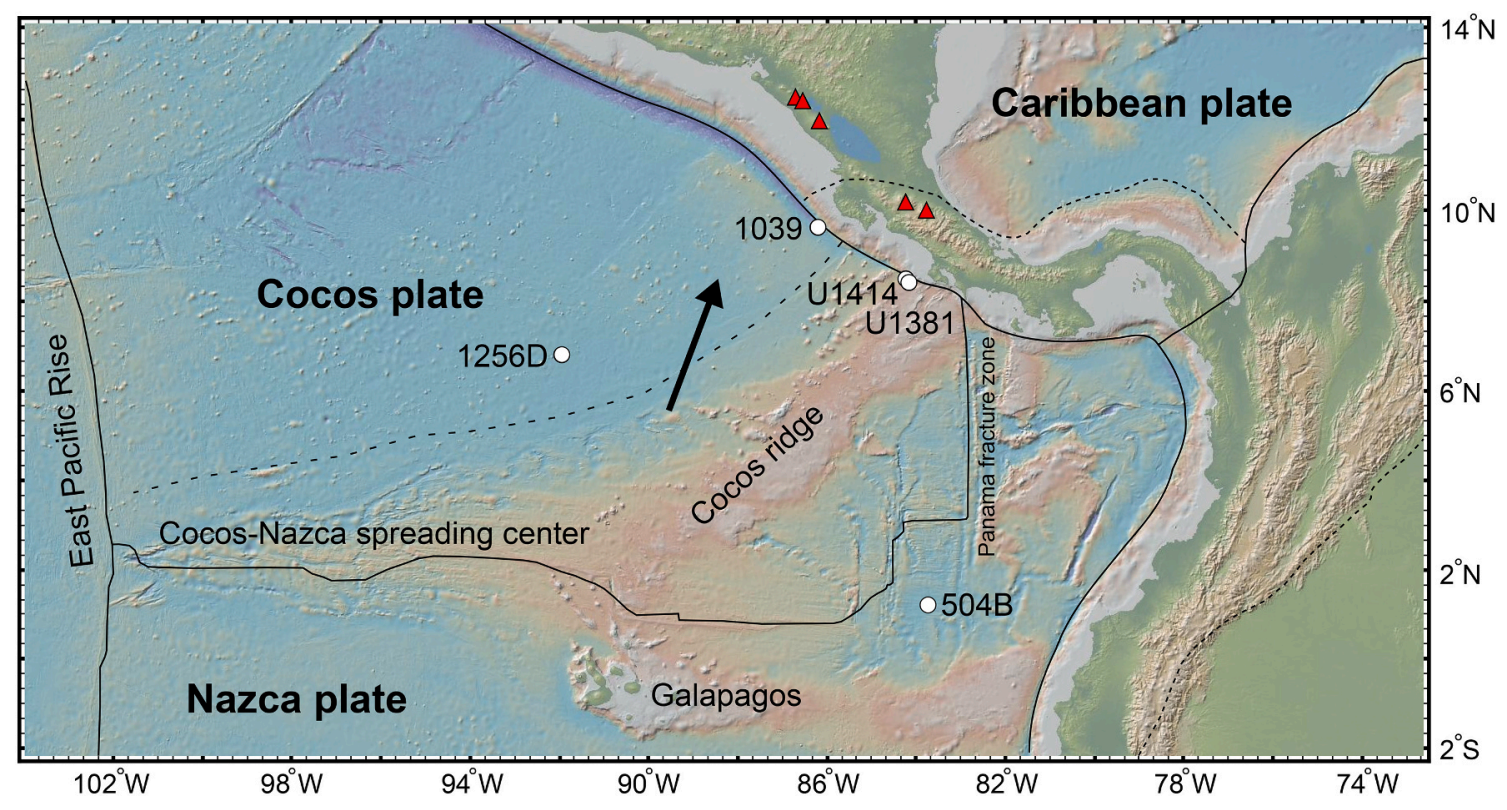

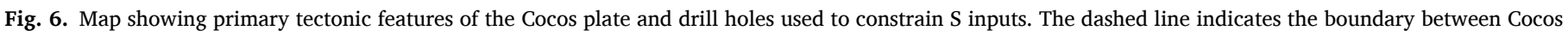
crust formed at the EPR and that formed at the CNS. 

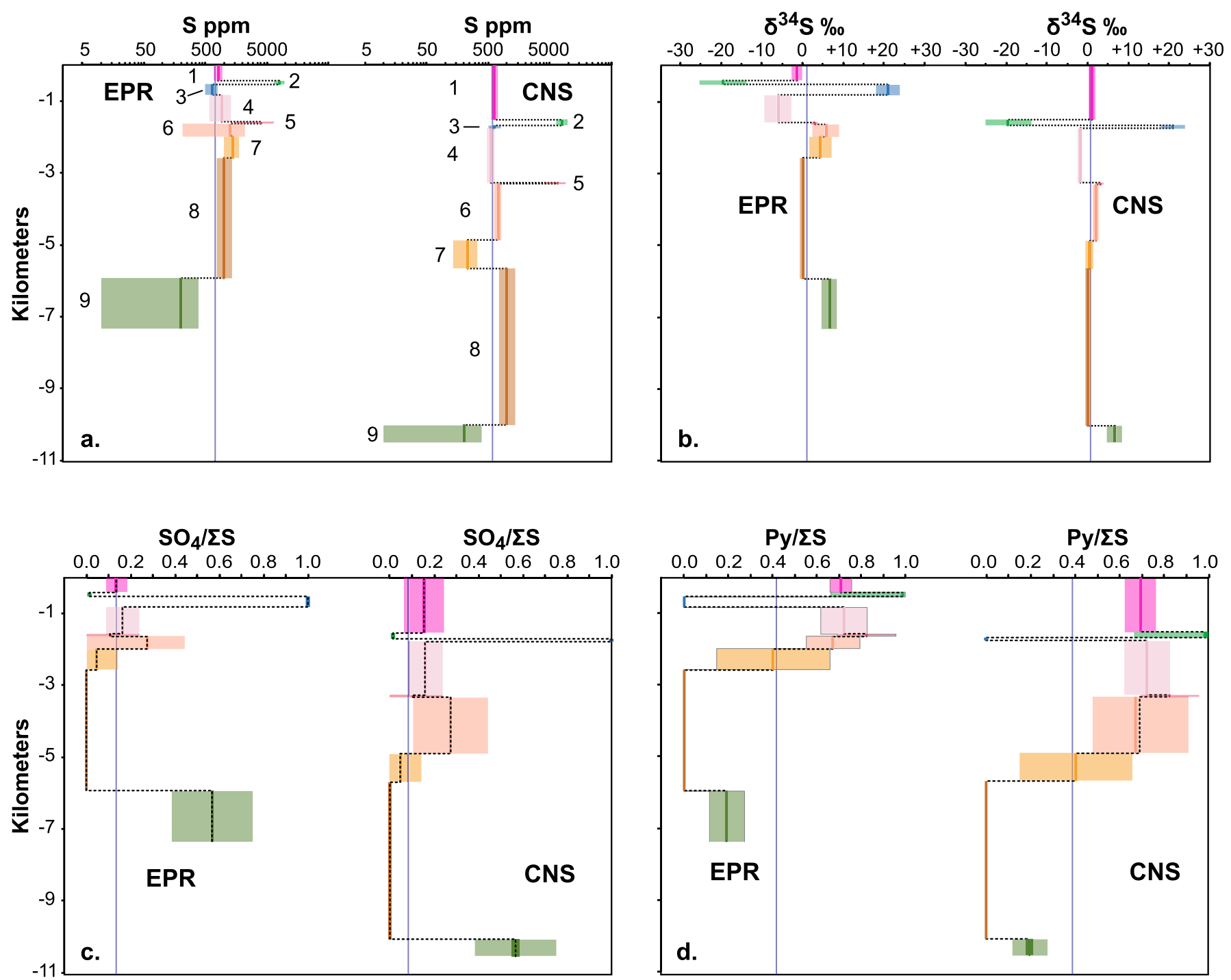

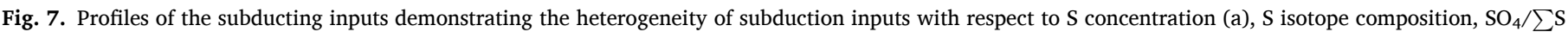

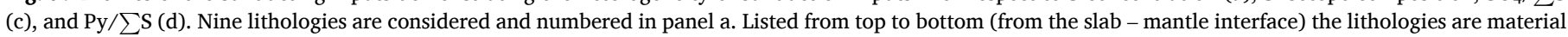

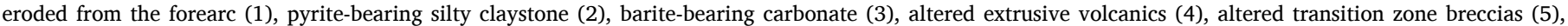

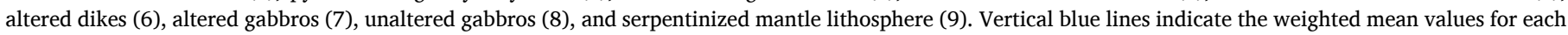

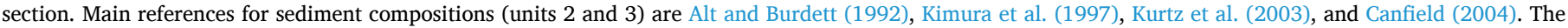

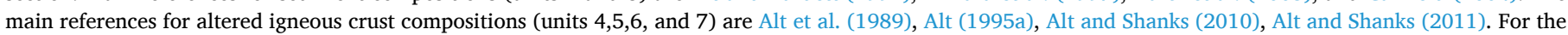

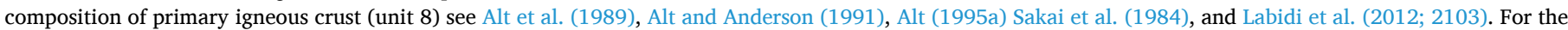

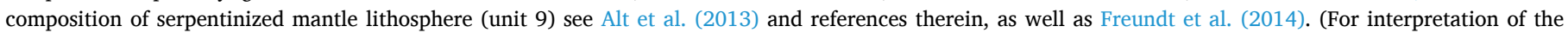
references to colour in this figure legend, the reader is referred to the web version of this article.)

sediments on the CNS plate have more relative influence on the total S budget than on the EPR plate due to their greater thickness compared to the pyrite-poor underlying sediments. The slightly more positive $\delta^{34} \mathrm{~S}$ of EPR total inputs could be a contributing factor to explain the isotopically heavier output calculated for Nicaragua $(+4.9 \pm 0.8 \%$ ) compared to Costa Rica $(+2.5 \pm 0.7 \%$ o). Subduction of the EPR segment is also associated with a higher input flux of oxidized S (Table 4).

\section{Mass balance modeling}

As shown above, the output of sulfur from SCAVA is isotopically heavier than the bulk input into the trench $(+3.8 \pm 1.7 \%$ for outputs versus $+0.7 \pm 0.4 \%$ o for inputs). This difference between input and output isotopic compositions requires a process that preferentially releases isotopically heavy sulfur form the slab. The flux of this isotopically heavy sulfur from the slab can be quantitatively modeled using our constraints on the arc outputs and inputs. It is the flux of this slab fluid that is the key parameter we investigate in terms of its potential to oxidize the mantle wedge and to affect the $\delta^{34} S$ value of material transported into the deep mantle. Arc output is derived from a combination of slab-derived and mantle-derived sulfur according to the relationship:

$$
\mathrm{F}_{\text {out }} \delta_{\text {out }}=\mathrm{F}_{\text {slab }} \delta_{\text {slab }}+\mathrm{F}_{\text {mantle }} \delta_{\text {mantle }}
$$

Where $\mathrm{F}$ is the flux, $\delta$ is the isotopic composition and subscripts out, slab and mantle refer to arc output, slab-derived, and mantle-derived S, respectively. Fluxes are expressed in units of mols/yr/100 km of convergence-perpendicular arc length to allow direct comparison between the Nicaraguan and Costa Rican arc segments $(308 \mathrm{~km}$ and 216 $\mathrm{km}$, respectively). Here we assume that mantle $\mathrm{S}$ has isotope composition of $\sim 0 \%$ (section 3.2.4), allowing the flux of $S$ from the slab to be calculated from: 

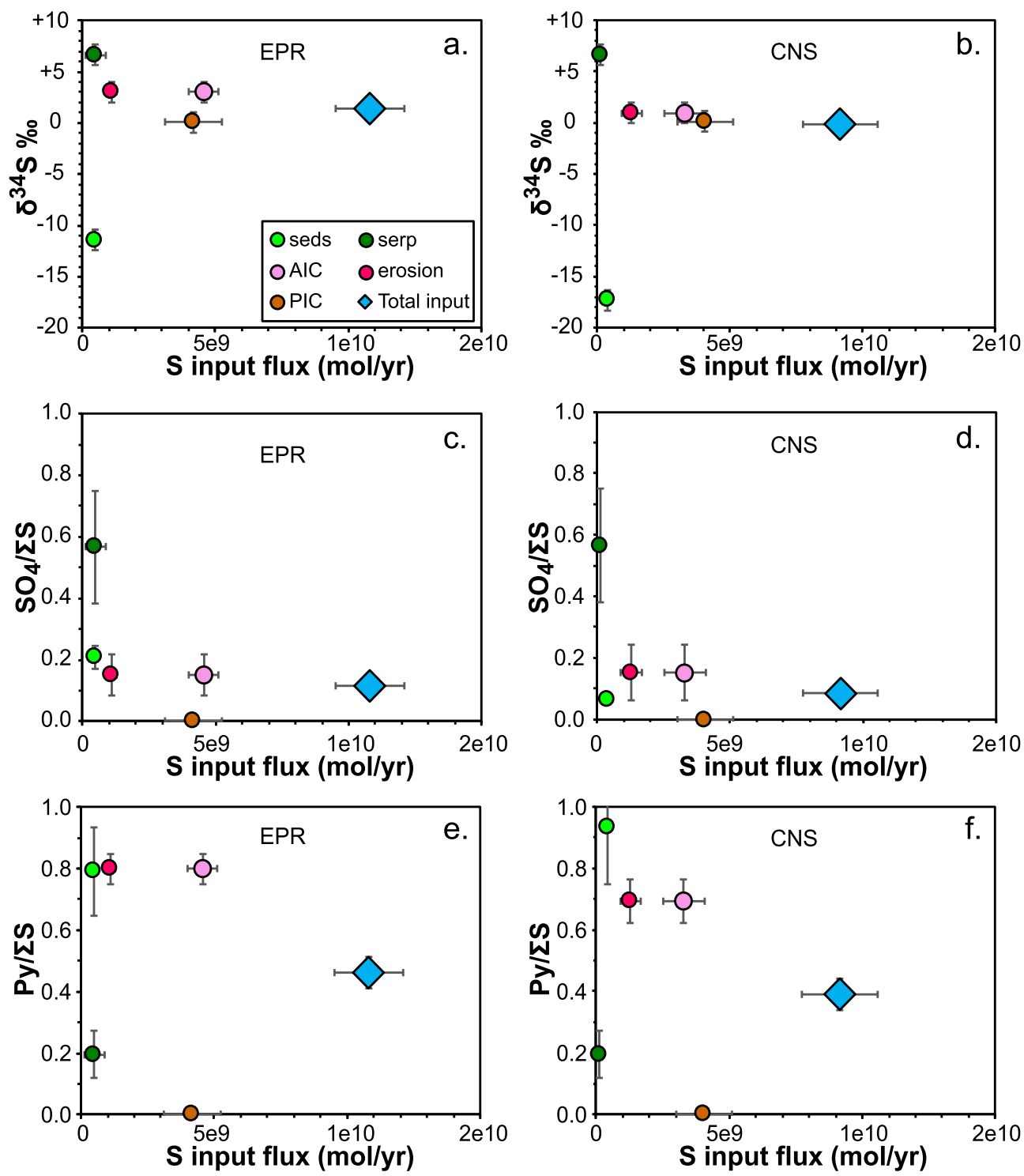

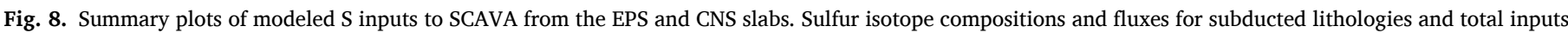

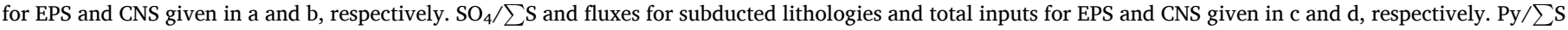
and fluxes for subducted lithologies and total inputs for EPS and CNS given in e and f, respectively.

$\mathrm{F}_{\text {slab }}=\mathrm{F}_{\text {out }} \delta_{\text {out }} / \delta_{\text {slab }}$

As we have constraints on $\mathrm{F}_{\text {out }}$ and $\delta_{\text {out }}$ (Table 2) the flux of $S$ from the slab $\left(\mathrm{F}_{\mathrm{slab}}\right)$ can be modeled as a function of the isotopic composition of slab fluids $\left(\delta_{\text {slab }}\right)$. The flux of sulfur from the mantle contributing to arc outputs is then:

$\mathrm{F}_{\text {mantle }}=\mathrm{F}_{\text {out }}-\mathrm{F}_{\text {slab }}$

The flux of sulfur to the deep mantle is:

$\mathrm{F}_{\mathrm{dm}}=\mathrm{F}_{\text {in }}-\mathrm{F}_{\text {slab }}$

where $F_{\text {in }}$ is the sulfur flux into the subduction zone (Table 4). The isotope composition of S subducted to the deep mantle is:

$\delta_{d m}=\frac{\mathrm{F}_{\text {in }} \delta_{\text {in }}-\mathrm{F}_{\text {slab }} \delta_{\text {slab }}}{\mathrm{F}_{\mathrm{dm}}}$

where $\delta_{\text {in }}$ is the $S$ isotope composition of bulk inputs (Table 4).

The flux of $S$ from the slab is a key parameter needed in order to constrain $\mathrm{S}$ mass balance through the subduction zone and can be modeled as a function of the $\delta^{34} \mathrm{~S}$ of slab fluid, as shown in Fig. 9, where the calculated flux from the slab decreases as the $\delta^{34} S$ of slab fluids increases. If the slab fluid contribution were very heavy, only a small amount of slab fluid would be required to explain the $\delta^{34} S$ of arc outputs, and the mantle would be the dominant contributor to arc outputs. If the $\delta^{34} \mathrm{~S}$ of slab fluids is close to that of arc outputs, then this would imply that slab fluids are the dominant source of $S$ emissions, with little mantle contribution. Because the arc output is fixed (Table 2) and derived from both slab and mantle $S$ (eq. 3) the mantle flux increases as the $\delta^{34} S$ of slab fluids increases (Fig. 9). Thus, the $\delta^{34} S$ of slab fluids is a key parameter in our model, determining the calculated $S$ fluxes from slab and mantle, as well as the flux and isotope composition of $\mathrm{S}$ returned to the deep mantle.

The correlations between $\delta^{34} \mathrm{~S}, \delta^{15} \mathrm{~N}$, and $\delta^{13} \mathrm{C}$ suggest that the endmember slab component has $\mathrm{S}$ isotope composition $\sim+8 \%$ (Fig. $3 \mathrm{~b}$ and c). Note that in our model the $\delta^{34} S$ of slab fluids is not dependent on the isotope composition of the subducted slab and is entirely independent of the $\mathrm{S}$ isotope composition of subducted components. Alternatively, Alt et al. $(1993,2012)$ have proposed that slab-derived sulfate- 


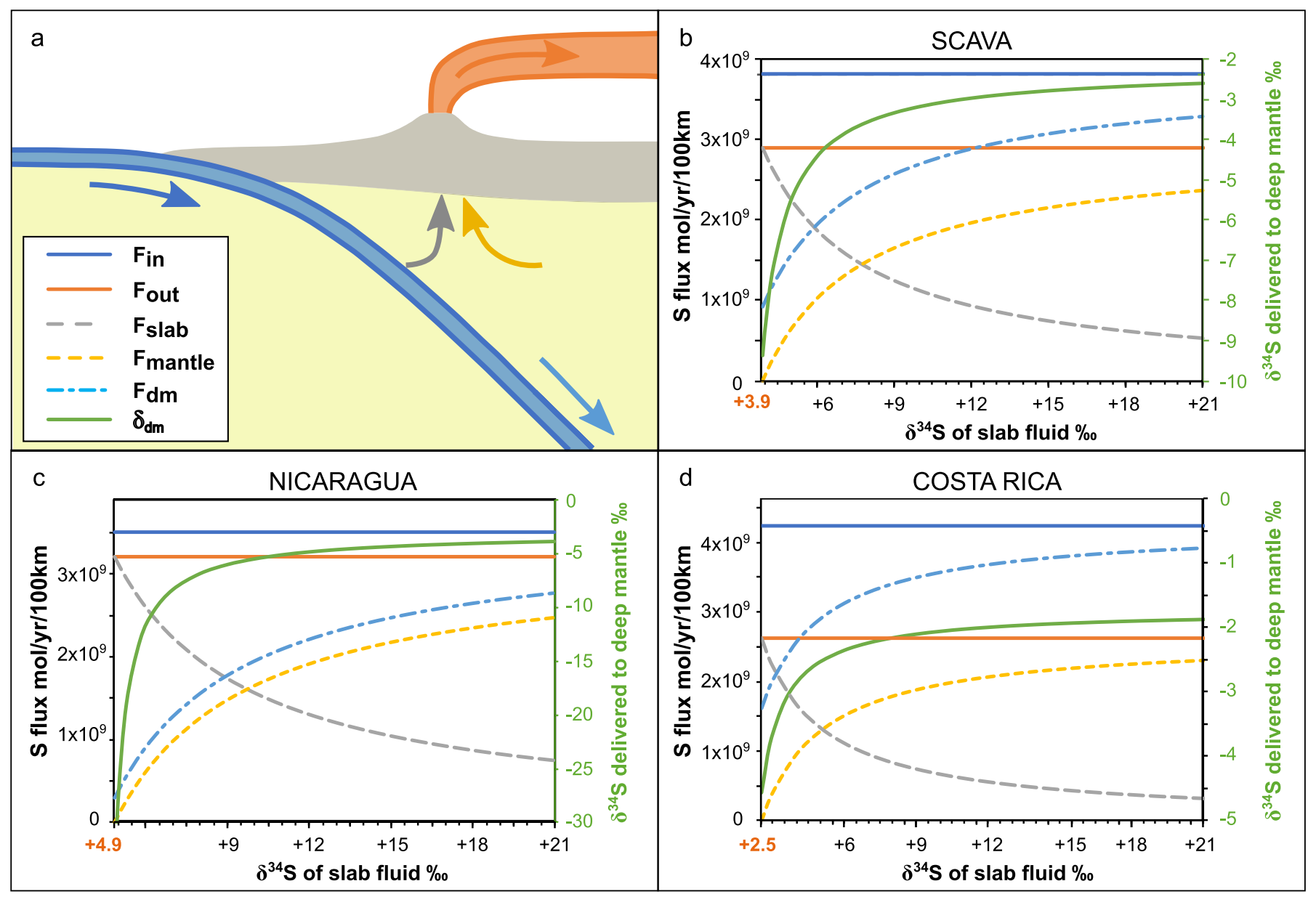

Fig. 9. Results of $S$ mass balance modeling as a function of the $S$ isotope composition of slab-derived fluids $\left(\delta_{\text {slab }}\right)$. Panel a shows the conceptual model where arc outputs are derived from a mixture of slab- and mantle-derived S, as well as the legend for the curves shown in panels b-d. Sulfur input fluxes ( $F_{\text {in }}$ ) and output fluxes $\left(\mathrm{F}_{\text {out }}\right)$ are fixed. Panels b, c, and d show the modeling results for SCAVA, Nicaragua, and Costa Rica, respectively. The $\mathrm{S}$ isotope composition of bulk outputs is the minimum value possible for $\delta_{\text {slab }}$ (orange values at the $\mathrm{x}$ axis origins) and would imply that all outputs are derived from the slab (i.e. $\mathrm{F}_{\text {slab }}=\mathrm{F}_{\text {out }}$ ) with no contribution from the mantle $\left(\mathrm{F}_{\text {mantle }}=0\right)$. The heaviest value of $\delta_{\text {slab }}$ considered in the model is that of seawater sulfate $(+21 \%)$. The heavier the isotope composition of the slabderived component, the lower the required flux thereof needed to account for the relatively heavy isotope composition of arc outputs. Uncertainties not shown for clarity (see Table 5).

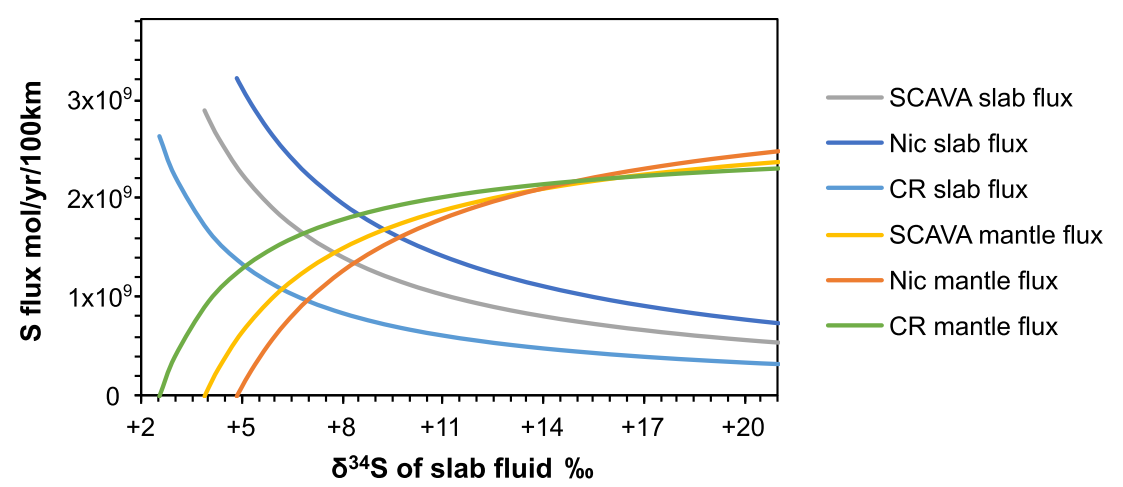

Fig. 10. Sulfur fluxes from the slab and mantle contributing to the arc output in Nicaragua (S output of $3.4 \times 10^{9} \mathrm{mols} / 100 \mathrm{~km} / \mathrm{yr}$ with $\delta^{34} \mathrm{~S}+4.78 \%$ ) versus Costa Rica (S output of $1.9 \times 10^{9} \mathrm{mols} / 100 \mathrm{~km} / \mathrm{yr}$ with $\delta^{34} \mathrm{~S}+2.3 \%$ ), as a function of the $\delta^{34} \mathrm{~S}$ value of slab-derived fluid. The intersection between mantle fluxes for Nicaragua and Costa Rica occurs at $\sim+15 \%$.

bearing fluids have an isotope composition of $\sim+14 \%$. Fig. 10 compares slab and mantle fluxes as a function of the isotopic composition of slab fluids for SCAVA, Nicaragua, and Costa Rica. The intersection between the mantle fluxes for Nicaragua and Costa Rica occurs at $\sim+$ $15 \%$, seeming to support the heavier slab fluid $\delta^{34} S$ proposed by Alt et al. $(1993,2012)$ if the mantle S fluxes along the arc were relatively similar. Thus, we consider two cases of slab fluid composition in further evaluation of $\mathrm{S}$ mass balance fluxes and tempo of mantle oxidation, the first with $\delta_{\text {slab }}$ of $+8 \%$ (Fig. 3 ) and the second with $\delta_{\text {slab }}$ of $+14 \%$. Flux model results are presented in Table 5 . 


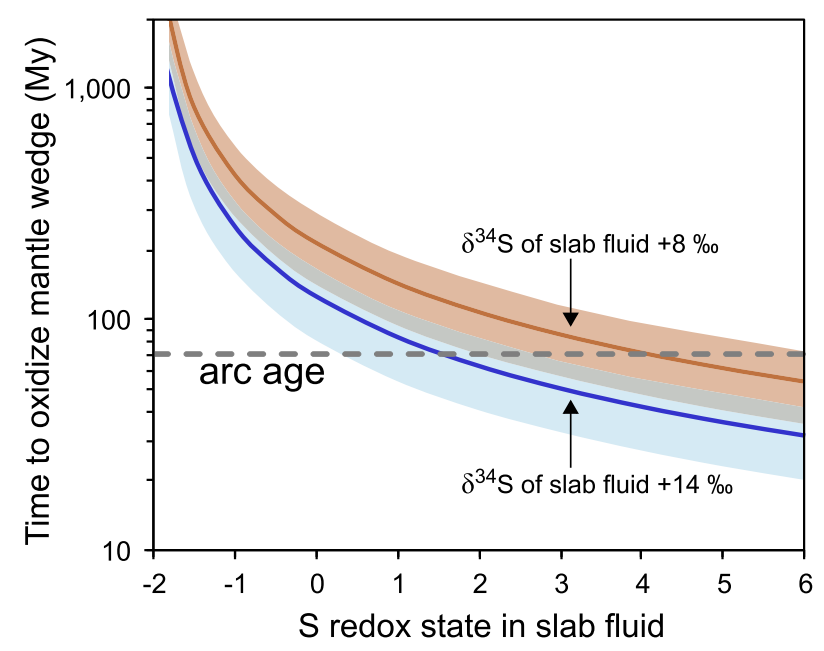

Fig. 11. Time to oxidize the entire mantle wedge as a function of $S$ oxidation state for the case of slab fluid flux modeled with $\delta_{\text {slab }}=+8 \%$ (brown line) and slab fluid flux modeled with $\delta_{\text {slab }}=+14 \%$ (blue line). Shaded regions indicate Monte Carlo errors. (For interpretation of the references to colour in this figure legend, the reader is referred to the web version of this article.)

\subsection{Sulfur mass balance fluxes}

The constraints on Nicaraguan S input and output fluxes and isotope compositions require a flux of $\mathrm{S}$ from the slab of $2.0 \pm 0.4 \times 10^{9} \mathrm{mols}$ / $\mathrm{yr} / 100 \mathrm{~km}$ if the $\mathrm{S}$ isotope composition of the slab fluid is $+8 \%$ o
(Table 5). This flux represents $56 \%$ of the $S$ input at the trench (i.e. $F_{\text {slab/ }}$ $\mathrm{F}_{\text {in }}$ ), contributing to $61 \%$ of the arc output (i.e. $\mathrm{F}_{\text {slab }} / \mathrm{F}_{\text {out }}$ ) with the remaining $49 \%$ delivered from the mantle (i.e. $\mathrm{F}_{\text {mantle }} / \mathrm{F}_{\text {out }}$ ). In Costa Rica the $\mathrm{S}$ isotope composition of arc output is lower than in Nicaragua $(+2.5 \pm 0.7 \%$ versus $+4.9 \pm 0.8 \%$ o $)$ requiring less delivery of isotopically heavy from the slab. The output flux of $S$ is also lower in Costa Rica than in Nicaragua. If $\delta_{\text {slab }}=+8 \%$, then a slab flux of $0.8 \pm 0.2 \times 10^{9}$ mols $/ \mathrm{yr} / 100 \mathrm{~km}$ is required for Costa Rica, significantly less than in Nicaragua and representing only $20 \%$ of the input flux at the trench. In this case, the relative contributions from slab and mantle to total $\mathrm{S}$ output flux from the Costa Rica arc are $32 \%$ and $68 \%$, respectively and $80 \%$ of the input flux at the trench is subducted beyond the arc to the deep mantle $\left(\mathrm{F}_{\mathrm{dm}} / \mathrm{F}_{\mathrm{in}}\right)$. Considering SCAVA as a whole, a slab flux of 1.4 $\pm 0.3 \times 10^{9} \mathrm{mols} / \mathrm{yr} / 100 \mathrm{~km}$ is required to account for the output flux of $2.9 \pm 0.8 \times 10^{9} \mathrm{mols} / \mathrm{yr} / 100 \mathrm{~km}$ with $\delta^{34} \mathrm{~S}$ of $+3.9 \pm 1.0 \%$. Thus, if $\delta_{\text {slab }}$ $=+8 \%$ o then $\sim 37 \%$ of the total input is recycled back out through the arc and $\sim 63 \%$ is subducted to the deep mantle. The total SCAVA output flux is composed of $49 \%$ slab S and $51 \%$ mantle S.

A heavier slab fluid isotope composition means that less slab fluid is required to account for the arc output $S$ isotope compositions and fluxes. With $\delta_{\text {slab }}=+14 \%$, a slab flux of $1.1 \pm 0.2 \times 10^{9} \mathrm{mols} / \mathrm{yr} / 100 \mathrm{~km}$ is calculated for Nicaragua, which is about half of the flux calculated for the case of $\delta_{\text {slab }}=+8 \%$, and represents $32 \%$ of the trench input (Table 5). In this case, $35 \%$ of the arc output is derived from the slab with the remaining $65 \%$ contributed from the mantle. The Costa Rica output flux and $\mathrm{S}$ isotope composition require just $11 \%$ contribution from slab fluids $\left(0.5 \pm 0.1 \times 10^{9} \mathrm{mols} / \mathrm{yr} / 100 \mathrm{~km}\right)$ with $\delta_{\text {slab }}=+14 \%$. We calculate a slab S flux of $1.5 \pm 0.3 \times 10^{9} \mathrm{mols} / \mathrm{yr} / 100 \mathrm{~km}$ for SCAVA with this heavy fluid composition, representing $21 \%$ of the total input, significantly less than the $37 \%$ calculated with $\delta_{\text {slab }}=+8 \%$. Therefore, a

Table 3

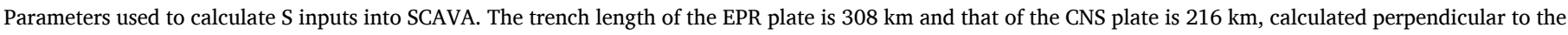
convergence angle from Syracuse and Abers (2006).

\begin{tabular}{|c|c|c|c|c|c|c|c|c|c|c|c|}
\hline & Units & Sediments & $1 \sigma$ & AIC & $1 \sigma$ & PIC & $1 \sigma$ & Serpentinite & $1 \sigma$ & Erosion & $1 \sigma$ \\
\hline \multicolumn{12}{|l|}{ EPR plate } \\
\hline Thickness & $\mathrm{m}$ & 401 & 133 & 1750 & 583 & 3350 & 1115 & 1400 & 933 & 422 & 211 \\
\hline Density & $\mathrm{kg} / \mathrm{m}^{3}$ & 715 & 64 & 2562 & 64 & 2934 & 36 & 2623 & 117 & 2562 & 64 \\
\hline S Conc & ppm & 2432 & 322 & 1487 & 190 & 620 & 180 & 200 & 200 & 1487 & 190 \\
\hline$\delta^{34} S$ & $\%$ & -11.4 & 3.0 & +3.0 & 1.6 & +0.1 & 0.5 & +6.6 & 1.9 & +3.0 & 1.6 \\
\hline $\mathrm{SO}_{4} / \sum \mathrm{S}$ & & 0.209 & 0.038 & 0.152 & 0.067 & 0 & 0 & 0.566 & 0.184 & 0.152 & 0.067 \\
\hline $\mathrm{Py} / \sum \mathrm{S}$ & & 0.791 & 0.142 & 0.799 & 0.049 & 0 & 0 & 0.195 & 0.077 & 0.799 & 0.049 \\
\hline \multicolumn{12}{|l|}{ CNS plate } \\
\hline Thickness & $\mathrm{m}$ & 240 & 160 & 3900 & 1524 & 4361 & 1452 & 467 & 311 & 1520 & 760 \\
\hline Density & $\mathrm{kg} / \mathrm{m}^{3}$ & 670 & 46 & 2609 & 69 & 2934 & 36 & 2623 & 117 & 2609 & 69 \\
\hline Concentration & ppm & 4953 & 629 & 634 & 60 & 620 & 180 & 200 & 200 & 634 & 60 \\
\hline$\delta^{34} S$ & $\%$ & -17.3 & 3.2 & +0.9 & 0.4 & +0.1 & 0.5 & +6.6 & 1.9 & +0.9 & 0.4 \\
\hline $\mathrm{SO}_{4} / \sum \mathrm{S}$ & & 0.065 & 0.013 & 0.152 & 0.090 & 0 & 0 & 0.566 & 0.184 & 0.152 & 0.090 \\
\hline $\mathrm{Py} / \sum \mathrm{S}$ & & 0.935 & 0.185 & 0.694 & 0.070 & 0 & 0 & 0.195 & 0.077 & 0.694 & 0.070 \\
\hline
\end{tabular}

Table 4

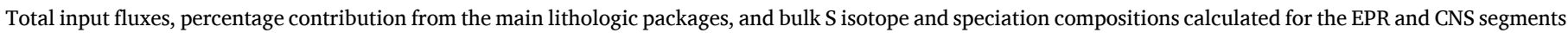
of the subducted slab, as well as for total SCAVA input.

\begin{tabular}{|c|c|c|c|c|c|c|c|c|c|c|}
\hline \multirow[b]{2}{*}{ Total S flux } & \multirow[b]{2}{*}{$\mathrm{mol} / \mathrm{yr}$} & \multicolumn{3}{|c|}{ EPR crust } & \multicolumn{3}{|c|}{ CNS crust } & \multicolumn{3}{|c|}{ SCAVA total input } \\
\hline & & $1.1 \mathrm{e} 10$ & \pm & $1.3 \mathrm{e} 9$ & $9.2 \mathrm{e} 9$ & \pm & $1.4 \mathrm{e} 9$ & $2.0 \mathrm{e} 10$ & \pm & $1.1 \mathrm{e} 9$ \\
\hline Erosion & $\%$ & 10.2 & \pm & 1.5 & 14.0 & \pm & 3.2 & 11.9 & \pm & 2.3 \\
\hline Sedimentary & $\%$ & 4.4 & \pm & 0.7 & 4.2 & \pm & 1.2 & 4.3 & \pm & 0.9 \\
\hline AIC & $\%$ & 42.2 & \pm & 5.1 & 36.0 & \pm & 7.0 & 39.4 & \pm & 6.0 \\
\hline PIC & $\%$ & 38.6 & \pm & 7.3 & 44.3 & \pm & 9.2 & 41.2 & \pm & 8.1 \\
\hline Serpentinite & $\%$ & 4.6 & \pm & 2.0 & 1.4 & \pm & 0.6 & 3.1 & \pm & 1.3 \\
\hline Bulk $\delta^{34} S$ & $\%$ & +1.4 & \pm & 0.5 & -0.2 & \pm & 0.4 & +0.7 & \pm & 0.4 \\
\hline $\mathrm{SO}_{4} / \sum \mathrm{S}$ & & 0.12 & \pm & 0.03 & 0.09 & \pm & 0.02 & 0.10 & \pm & 0.01 \\
\hline $\mathrm{Py} / \sum \mathrm{S}$ & & 0.46 & \pm & 0.05 & 0.39 & \pm & 0.05 & 0.43 & \pm & 0.02 \\
\hline$S^{6+}$ input flux & $\mathrm{mol} / \mathrm{yr}$ & $1.25 \mathrm{e} 9$ & \pm & $2.39 \mathrm{e} 8$ & 7.91e8 & \pm & $1.45 \mathrm{e} 8$ & $2.04 \mathrm{e} 9$ & \pm & $2.39 \mathrm{e} 8$ \\
\hline $\mathrm{S}^{-}$input flux & $\mathrm{mol} / \mathrm{yr}$ & $5.00 \mathrm{e} 9$ & \pm & $4.71 \mathrm{e} 8$ & $3.57 \mathrm{e} 9$ & \pm & $4.15 \mathrm{e} 8$ & $8.57 \mathrm{e} 9$ & \pm & $6.22 \mathrm{e} 8$ \\
\hline $\mathrm{S}^{2-}$ input flux & $\mathrm{mol} / \mathrm{yr}$ & $4.57 \mathrm{e} 9$ & \pm & $5.81 \mathrm{e} 8$ & $4.80 \mathrm{e} 9$ & \pm & $8.55 \mathrm{e} 8$ & $9.37 \mathrm{e} 9$ & \pm & $2.44 \mathrm{e} 8$ \\
\hline
\end{tabular}


Table 5

Mass balance modeling results for S fluxes for $\delta_{\text {slab }}=+8 \%$ and $\delta_{\text {slab }}=+14 \%$. Fluxes given in mols $/ \mathrm{yr} / 100 \mathrm{~km}$.

\begin{tabular}{|c|c|c|c|c|c|c|c|c|c|c|c|c|c|c|c|c|c|}
\hline & $\delta_{\text {slab }}$ & $F_{\text {in }}$ & \pm & $F_{\text {out }}$ & \pm & $\mathrm{F}_{\text {slab }}$ & \pm & $F_{\text {mantle }}$ & \pm & $\mathrm{F}_{\mathrm{dm}}$ & \pm & $\delta_{\mathrm{dm}}$ & \pm & $\begin{array}{c}\mathrm{F}_{\text {slab }} / \\
\mathrm{F}_{\text {in }}\end{array}$ & $\begin{array}{c}\mathrm{F}_{\text {slab }} / \\
\mathrm{F}_{\text {out }}\end{array}$ & $\begin{array}{c}\mathrm{F}_{\text {mantle }} / \\
\mathrm{F}_{\text {out }}\end{array}$ & $\begin{array}{c}\mathrm{F}_{\mathrm{dm}} / \\
\mathrm{F}_{\mathrm{in}}\end{array}$ \\
\hline \multirow[t]{2}{*}{ Nicaragua } & 8 & $3.5 \mathrm{e} 9$ & $4.2 \mathrm{e} 8$ & $3.2 \mathrm{e} 9$ & $8.8 \mathrm{e} 8$ & $2.0 \mathrm{e} 9$ & $3.6 \mathrm{e} 8$ & $1.3 \mathrm{e} 9$ & $2.7 \mathrm{e} 8$ & $1.6 \mathrm{e} 9$ & $4.3 e 8$ & -6.83 & 5.36 & 0.56 & 0.61 & 0.39 & 0.44 \\
\hline & 14 & $3.5 \mathrm{e} 9$ & $4.2 \mathrm{e} 8$ & 3.2Ee9 & $8.8 \mathrm{e} 8$ & $1.1 \mathrm{e} 9$ & $2.0 \mathrm{e} 8$ & $2.1 \mathrm{e} 9$ & $3.5 \mathrm{e} 8$ & $2.4 \mathrm{e} 9$ & $3.1 \mathrm{e} 8$ & -4.44 & 1.82 & 0.32 & 0.35 & 0.65 & 0.68 \\
\hline \multirow[t]{2}{*}{ Costa Rica } & 8 & $4.2 \mathrm{e} 9$ & $6.6 \mathrm{e} 8$ & $2.6 \mathrm{e} 9$ & $6.8 \mathrm{e} 8$ & $8.3 \mathrm{e} 8$ & $1.8 \mathrm{e} 8$ & $1.8 \mathrm{e} 9$ & $3.0 \mathrm{e} 8$ & $3.4 \mathrm{e} 9$ & $4.2 \mathrm{e} 8$ & -2.17 & 0.69 & 0.20 & 0.32 & 0.68 & 0.80 \\
\hline & 14 & $4.2 \mathrm{e} 9$ & $6.6 \mathrm{e} 8$ & $2.6 \mathrm{e} 9$ & $6.8 \mathrm{e} 8$ & $4.8 \mathrm{e} 8$ & $1.1 \mathrm{e} 8$ & $2.1 \mathrm{e} 9$ & $3.3 \mathrm{e} 8$ & $3.8 \mathrm{e} 9$ & $3.9 \mathrm{e} 8$ & -1.96 & 0.55 & 0.11 & 0.18 & 0.82 & 0.89 \\
\hline \multirow[t]{2}{*}{ SCAVA } & 8 & $3.8 \mathrm{e} 9$ & $2.1 \mathrm{e} 8$ & $2.9 \mathrm{e} 9$ & $8.0 \mathrm{e} 8$ & $1.4 \mathrm{e} 9$ & $3.0 \mathrm{e} 8$ & $1.5 \mathrm{e} 9$ & $3.1 \mathrm{e} 8$ & $2.4 \mathrm{e} 9$ & $3.2 \mathrm{e} 8$ & -3.58 & 1.62 & 0.37 & 0.49 & 0.51 & 0.63 \\
\hline & 14 & $3.8 \mathrm{e} 9$ & $2.1 \mathrm{e} 8$ & $2.9 \mathrm{e} 9$ & $8.0 \mathrm{e} 8$ & $8.0 \mathrm{e} 8$ & $1.7 \mathrm{e} 8$ & $2.1 \mathrm{e} 9$ & $3.5 \mathrm{e} 8$ & $3.0 \mathrm{e} 9$ & $2.1 \mathrm{e} 8$ & -2.86 & 1.04 & 0.21 & 0.28 & 0.72 & 0.79 \\
\hline
\end{tabular}

slab fluid isotope composition $\delta_{\text {slab }}=+14 \%$ o suggests a factor of $\sim 2$ more efficient subduction of $S$ to the deep mantle and proportionally less slab contribution to arc outputs.

\section{Implications for S cycling and mantle chemistry}

\subsection{Preferential release of oxidized sulfur from the slab}

Our constraints on $S$ input and output fluxes and their relative isotope compositions combined with mass balance modeling results show that the $S$ isotope composition of slab fluids must be isotopically heavy relative to bulk inputs and that a significant proportion of $S$ input is subducted beyond the arc to the deeper mantle. The assertion that these fluids must be isotopically heavy $(+8 \%$ o to $+14 \%$ ) suggests that they are also oxidized, because the heavy isotope of $S$ preferentially partitions into more oxidized S species (e.g. Evans et al., 2014) and further implies that oxidized sulfur is preferentially released from the slab beneath the arc. This is consistent with the findings of Tomkins and Evans (2015) who modeled the solubilities of anhydrite and pyrite in subducted oceanic crust and found that anhydrite breaks down at significantly lower temperatures than pyrite, arguing for preferential release of oxidized $\mathrm{S}$ beneath the subarc mantle. Furthermore, fluid release from the slab occurs at relatively low temperatures $\left(620^{\circ} \mathrm{C}-\right.$ $800{ }^{\circ} \mathrm{C}$; Peacock et al., 2005) compared to magmatic processes (e.g. degassing; section 3.2 .5 ) so isotopic fractionation between diverse $\mathrm{S}$ minerals in the slab and slab-derived fluids is inherently favored.

Our sulfur isotope mass balance modeling for SCAVA indicates that $20 \%$ to $40 \%$ of the subducted $S$ is released from the slab and the heavy isotopic composition (required by the fact that arc outputs are isotopically heavy) of this fluid suggests that sulfur is dominantly released in a relatively oxidized state. However, the $S^{6+} / \sum S$ value in the bulk subducted slab is low and in the range of 0.09 to 0.12 . The total $\mathrm{S}^{6+}$ flux into SCAVA is calculated at $2.04 \pm 0.24 \times 10^{9} \mathrm{~mol} / \mathrm{yr}$ (Table 4) whereas the flux of (oxidized) $S$ from the slab is calculated at $7.4 \times 10^{9}$ to $4.2 \times 10^{9}$ $\mathrm{mol} / \mathrm{yr}$. This could suggest that there is significantly more oxidized $\mathrm{S}$ in the downgoing slab than suggested by available drill hole data and is consistent with the idea that faulting on the outer rise just before subduction drives significant seawater circulation and fixation of sulfate (e. g. Alt et al., 2013). No holes have been drilled into the post-outer rise subducting slab, therefore this is an open question. Alternatively, S may be oxidized in the downgoing slab during subduction by reaction with oxidized elements such in the slab such as $\mathrm{Fe}^{3+}$ (Walters et al., 2020) and carbonate, both of which are abundant (Evans, 2012).

\subsection{Tempo of mantle wedge oxidation}

Sulfur in slab-derived fluids is potentially a strong oxidant, playing an important role in the redox state of arc magmas. The mass balance modeling of the flux of $S$ released from the slab allows for a novel approach to assess the tempo of mantle wedge oxidation due to sulfur release from the slab. If the $S$ flux from the slab and the redox state thereof are known, the oxidizing potential of the slab fluids can be calculated. We model this process as the time it would take to increase all the oxidation state of iron in the mantle wedge from $\mathrm{Fe}^{3+} / \sum \mathrm{Fe} 0.15$ to 0.25 (Kelley and Cottrell, 2009), given the calculated S flux from the slab (Figs. 9 and 10). The total moles of Fe in the mantle wedge is calculated from the trench length $(524 \mathrm{~km})$, the distance from the trench to the volcanic arc $(173 \mathrm{~km}$ ), and an $\mathrm{FeO}$ content of $8 \mathrm{wt} \%$ (Syracuse and Abers, 2006; Workman and Hart, 2005). The number of moles of electrons lost from $\mathrm{Fe}^{2+}$ needed to raise $\mathrm{Fe}^{3+} / \sum \mathrm{Fe}$ in the mantle wedge from 0.15 to 0.25 is then calculated. Sulfur in slab fluids is likely oxidized, as argued above, but the specific oxidation state of these fluids is not known. The more oxidized the $S$ in the slab fluids, the less time required to oxidize mantle $\mathrm{Fe}$ from $\mathrm{Fe}^{3+} / \sum \mathrm{Fe} 0.15$ to 0.25 . To illustrate, if $\mathrm{S}$ released from the slab were in its most oxidized state $\left(\mathrm{S}^{6+}\right)$ every mole of $S$ fluxed from the slab could accept electrons from $8 \mathrm{~mol}$ of $\mathrm{Fe}^{2+}$, producing $\mathrm{S}^{2-}$ and $\mathrm{Fe}^{3+}$. If slab-derived $\mathrm{S}$ were in the $\mathrm{S}^{2+}$ state, every mole of $\mathrm{S}$ fluxed from the slab could accept $4 \mathrm{~mol}$ of electrons from $\mathrm{Fe}^{2+}$. Therefore, the time to oxidize the mantle wedge would be a factor of two lower in the case of slab fluids with $\mathrm{S}^{2+}$ compared to the case of slab fluids carrying $\mathrm{S}^{6+}$.

Given the framework described above, we model the time to oxidize the mantle wedge as a function of the redox state of $S$ in the slab fluid (Fig. 11) for SCAVA considering the two cases of $\delta_{\text {slab }}$ composition (section 4.1). The entire mantle wedge can be oxidized within the lifetime of the arc ( $\sim 71 \mathrm{Ma}$; Gazel et al., 2021) if the slab fluids have S redox state higher than $\sim 1$ for the higher slab flux scenario associated with $\delta_{\text {slab }}$ of $+8 \%$. Alternatively, the $\mathrm{S}$ redox state would have to be significantly higher $(\sim 4)$ if the lower slab flux scenario is considered (i.e. with $\delta_{\text {slab }}$ of $+14 \%$ ). Here it is important to note that it is not necessary to oxidize the entire mantle wedge to generate oxidized arc basalts. Rather, only the volume directly affected by metasomatic fluids need undergo oxidation (Evans and Tomkins, 2011; Brounce et al., 2015). The Nicaraguan arc, characterized by higher $S$ output and isotopically heavier S emissions, suggests higher flux of oxidizing slab fluids to the mantle wedge. Costa Rican volcanism is associated with lower S output and isotopically lighter S emissions, suggesting lower flux of oxidizing slab fluids to the mantle wedge and less oxidizing potential.

Rielli et al. (2017) considered $\mathrm{SO}_{4}{ }^{2-}\left(6+\right.$ redox state) and $\mathrm{S}_{3}{ }^{-}$ (average redox state of 0.33 -) as possible $\mathrm{S}$ species in slab-derived fluids. Both of these species are oxidizing agents capable of oxidizing $\mathrm{Fe}^{2+}$ by reduction of $\mathrm{S}$ to the 2- redox state, with $\mathrm{SO}_{4}{ }^{2-}$ capable of oxidizing 8 mols of Fe per mol of S. Brounce et al. (2014) showed a positive correlation between $\mathrm{Ba}$ enrichment and oxidation state in arc basalts, consistent with the breakdown of subducted sedimentary barite $\left(\mathrm{BaSO}_{4}\right)$ during subduction. The more efficient release of sulfate from the slab in Nicaragua (relative to Costa Rica) is consistent with high Ba/La (Fig. 3f), the heavier $\mathrm{S}$ isotope compositions in arc emissions and higher modeled slab-derived S flux.

It has been recognized that carbon plays an important role in subduction oxidation, during the reduction of slab-derived $\mathrm{C}$ to diamond or graphite (e.g. Rielli et al., 2017). Our data show that heavy $\delta^{34} S$ in arc emissions is also associated with high $\mathrm{CO}_{2} / \mathrm{S}_{\mathrm{t}}$ (Fig. 3d), attributed to greater contribution of slab-derived carbon (Aiuppa et al., 2014). Thus, the oxidizing potential of Nicaraguan slab fluids may be further enhanced by higher $\mathrm{C} / \mathrm{S}$ than Costa Rican slab fluids.

\subsection{Sulfur subduction to the deep mantle}

If isotopically heavy $S$ is preferentially released from the slab, this 
must be accompanied by retention in the residual slab of $S$ that is more isotopically negative $\left(\delta_{\mathrm{dm}}\right.$; Fig. 9$)$ than the bulk subduction inputs. The amount and isotope composition of $S$ subducted beyond the arc will depend on how much $S$ is lost from the slab and the $S$ isotope composition of the fluids that were lost (i.e. $\delta_{\text {slab }}$ ). For the case of SCAVA and $\delta_{\text {slab }}=+8 \%$, we calculate that $2.4 \pm 0.3 \times 10^{9} \mathrm{mols} / \mathrm{yr} / 100 \mathrm{~km}$ is subducted beyond the arc, carrying a sulfur isotope composition of -3.6 $\pm 1.6 \%$ into the deep mantle (Table 5 ). If $\delta_{\text {slab }}=+14 \%$ then the flux of $S$ to the deep mantle is $3.0 \pm 0.2 \times 10^{9}$ with $\delta^{34} \mathrm{~S}=-2.9 \pm 1.0 \%$.

The bulk $\mathrm{S}$ isotope composition of Earth's surface reservoirs (crust + oceans) is $\sim+3 \%$ (Canfield, 2004). The subduction of isotopically negative $S$ to the deep mantle, with isotopically heavy $S$ recycled to the surface through subduction zones, is a reasonable explanation for the positive $\mathrm{S}$ isotope composition of the surface reservoir. If the total sulfur surface inventory of the Earth (ocean + crust $=\sim 5.33 \times 10^{20} \mathrm{mols} \mathrm{S}$ ) is divided by the $\mathrm{S}$ flux from the mantle $\left(\sim 2.67 \times 10^{12} \mathrm{mols} / \mathrm{yr} \mathrm{S}\right)$ the mean degassing duration for $\mathrm{S}$ of $2 \times 10^{8} \mathrm{yrs}$. is derived (Hilton et al., 2002). This value is low compared to more volatile elements such as $\mathrm{CO}_{2}$ $\left(2 \times 10^{9} \mathrm{yrs}\right), \mathrm{N}_{2}\left(2 \times 10^{11} \mathrm{yrs}\right)$, and ${ }^{3} \mathrm{He}\left(9 \times 10^{10} \mathrm{yrs}\right)$, indicating relatively efficient sulfur exchange between the surface and mantle reservoirs (Hilton et al., 2002). If we consider the value of $-3 \%$ for the isotope composition for $\mathrm{S}$ delivered to the deep mantle through subduction ( $\delta \mathrm{dm}$; Table 5 ), then $\sim 5.33 \times 10^{20}$ mols of subducted $S$ must balance the isotope composition and mass of $S$ in the current surface reservoirs. If the $\mathrm{S}$ content of the primitive mantle is $250 \mathrm{ppm}$ (McDonough and Sun, 1995), then the lower mantle contains $\sim 1.5 \times 10^{22} \mathrm{mols}$ of $S$ and introduction of $2.7 \times 10^{20}$ mols of subducted $S$ with an isotope composition of $-3 \%$ would result in only minor modification of the $S$ isotope composition of the mantle $(\sim 0.1 \%)$ if well mixed.

It is important to consider that the size and sulfur isotope composition of the surface reservoir has changed over geologic time (Canfield, 2004). During periods of sulfidic oceanic conditions and high pyrite subduction, the $\delta^{34} S$ of the surface reservoir may have been as high as $+20 \%$, and the surface inventory was up to ten times that of the present surface inventory (Canfield, 2004), suggesting enhanced subduction of isotopically light $\mathrm{S}$. Notably, both positive and negative $\delta^{34} \mathrm{~S}$ values are observed in OIB, diamond inclusions, and upper mantle-derived rocks (Sakai et al., 1984; Labidi et al., 2013, 2015; Delavault et al., 2016; Beaudry et al., 2018; Smit et al., 2019; Dottin III et al., 2020) suggesting that the mantle is not well mixed with respect to $S$. The $S$ isotope composition of subducted pyrite has also varied significantly over time. Indeed, during the early Phanerozoic and Neoproterozoic the $\delta^{34} S$ of sedimentary pyrite was isotopically positive, with average values in the range of $\sim+10 \%$ and ranging up to $+50 \%$ o (Strauss, 1997; Canfield, 2004), likely contributing to mantle heterogeneities when subducted.

\section{Conclusions}

Sulfur isotope compositions of high temperature volcanic gases from Nicaragua (average of $+4.8 \pm 1.4 \%$ ) and Costa Rica $(+2.3 \pm 1.3 \%$ ) exhibit correlations with along-arc geochemical tracers consistent with mixing between mantle fluids with $\delta^{34} \mathrm{~S} \sim 0 \%$ and an isotopically heavy slab-derived endmember with $\delta^{34} \mathrm{~S}$ greater than $+7 \%$. The total $\mathrm{S}$ output budget of the Southern Central American Volcanic Arc is strongly dominated by degassing from open vent volcanoes and excess $\mathrm{S}$ degassing is thus observed at the regional scale and is not limited to individual volcanic eruptions. Mass balance modeling of subduction inputs indicate that bulk $S$ input $(+0.7 \pm 04 \%$ for the whole SCAVA system) is significantly lighter than arc outputs, suggesting that isotopically heavy oxidized $S$ is preferentially released from the slab at subarc depths. Mass balance modeling of $\mathrm{S}$ recycling through the subduction zone indicates that $20 \%$ to $40 \%$ of the total subducted $S$ is released from the slab and recycled back to surface reservoirs. This flux of oxidized $S$ is enough to oxidize the entire mantle wedge within the lifetime of the arc if the average oxidation state of $S$ in the slab-derived fluids is greater than $1+$. Our modeling predicts that primitive magmas from the Nicaraguan arc segment are more oxidized than those in Costa Rica due to the greater influence of slab fluids on magma genesis. Considering that isotopically heavy sulfur is preferentially released from the slab, it stands to reason that residual reduced slab S introduced to the deep mantle must be isotopically negative. Sedimentary sulfides from the early Phanerozoic and Proterozoic, however, are isotopically positive suggesting that reduced $S$ retained in subducting slabs in the early Earth may have introduced positive $\delta^{34} S$ values to some regions of the deep mantle.

\section{Declaration of Competing Interest}

The authors declare that they have no known competing financial interests or personal relationships that could have appeared to influence the work reported in this paper.

\section{Acknowledgements}

This research was supported by the National Science Foundation through grant EAR1049891 (TF), by a NASA Earth and Space Science Fellowship to JMdM/Penelope King (Planet09F-0044), and by NSF grant number 1850699 to JMdM. This work was also supported by funding from the Costa Rican Ley Transitorio 8933 and from the Universidad Nacional, Costa Rica, through project PPA0031-18. Viorel Atudorei is gratefully acknowledged for guidance in the sulfur isotope analyses. Erick Fernández is thanked for collecting excellent gas samples from Poás and Turrialba. JMdM thanks Zach Sharp, Penny King, and Scott Jasechko for helpful discussions that influenced this paper.

\section{Appendix A. Supplementary data}

Supplementary data to this article can be found online at https://doi. org/10.1016/j.chemgeo.2021.120627.

\section{References}

Aiuppa, A., Robidoux, P., Tamburello, G., Conde, V., Galle, B., Avard, G., Bagnato, E., De Moor, J.M., Martinez, M., Muñóz, A., 2014. Gas measurements from the Costa RicaNicaragua volcanic segment suggest possible along-arc variations in volcanic gas chemistry. Earth Planet. Sci. Lett. 407, 134-147.

Aiuppa, A., Fischer, T.P., Plank, T., Robidoux, P., Di Napoli, R., 2017. Along-arc, inter-arc and arc-to-arc variations in volcanic gas $\mathrm{CO} 2 / \mathrm{ST}$ ratios reveal dual source of carbon in arc volcanism. Earth Sci. Rev. 168, 24-47.

Aiuppa, A., Fischer, T.P., Plank, T., Bani, P., 2019. CO2 flux emissions from the Earth's most actively degassing volcanoes, 2005-2015. Sci. Rep. 9, 5442.

Alt, J.C., 1995a. Sulfur isotopic profile through the oceanic-crust - Sulfur sobility and seawater-crustal sulfur exchange during hydrothermal alteration. Geology 23, 585-588.

Alt, J.C., 1995b. Seafloor processes in mid-ocean ridge hydrothermal systems. In: Humphris. In: Humphris, S.E., Zierenberg, R.A., Millineaux, L.S., Thomson, R.E. (Eds.), Seafloor Hydrothermal Systems: Physical, Chemical, Biological, and Geological Interactions. American Geophysical Union, Washington, DC, pp. 85-114.

Alt, J.C., Anderson, T.F., 1991. The mineralogy and isotopic composition of sulfur in Layer 3 gabbros from the Indian Ocean, ODP Hole 735B. In: Robinson, P.T., Von Herzen, R., et al. (Eds.), Proceedings of the Ocean Drilling Program, Scientific Results, Volume 118: College Station, Texas, Ocean Drilling Program, pp. 113-125.

Alt, J.C., Burdett, J., 1992. Sulfur in Pacific deep-sea sediments, ODP Leg 129, and implications for cycling of sediment in subduction zones. In: Proceedings of the Ocean Drilling Program, Scientific Results, 129, pp. 283-294.

Alt, J.C., Shanks, W.C., 2010. Sulfur exchange between seawater and oceanic basement. Goldschmidt Conference Abstracts 2010, A15.

Alt, J.C., Shanks, W.C., 2011. Microbial sulfate reduction and the sulfur budget for a complete section of altered oceanic basalts, IODP Hole 1256D (eastern Pacific). Earth Planet. Sci. Lett. 310, 73-83.

Alt, J.C., Anderson, T.F., Bonnell, L., 1989. The geochemistry of sulfur in a $1.3 \mathrm{~km}$ section of hydrothermally altered oceanic crust, DSDP Hole 504B. Geochim. Cosmochim. Acta 53 (5), 1011-1023.

Alt, J.C., Shanks, W.C., Jackson, M.C., 1993. Cycling of sulfur in subduction sones - the geochemistry of sulfur in the Mariana-island arc and back-arc trough. Earth Planet. Sci. Lett. 119, 477-494.

Alt, J.C., Laverne, C., Coggon, R.M., Teagle, D.A., Banerjee, N.R., Morgan, S., SmithDuque, C.E., Harris, M., Galli, L., 2010. Subsurface structure of a submarine hydrothermal system in ocean crust formed at the East Pacific Rise, ODP/IODP Site 1256. Geochem. Geophys. Geosyst. 11 (10). 
Alt, J.C., Garrido, C.J., Shanks, W.C., Turchyn, A., Padron-Navarta, J.A., SanchezVizcaino, V.L., Pugnaire, M.T.G., Marchesi, C., 2012. Recycling of water, carbon, and sulfur during subduction of serpentinites: a stable isotope study of Cerro del Almirez. Spain Earth Planet. Sci. Lett. 327, 50-60.

Alt, J.C., Shanks, W.C., Crispini, L., Gaggero, L., Schwarzenbach, E., Früh-Green, G., Bernasconi, S., 2013. Uptake of carbon and sulfur during seafloor serpentinization and the effects of subduction metamorphism in Ligurian serpentinites. Chem. Geol. 322-323, 268-277. https://doi.org/10.1016/j.chemgeo.2012.07.009.

Andres, R.J., Kasgnoc, A.D., 1998. A time-averaged inventory of subaerial volcanic sulfur emissions. J. Geophys. Res.-Atmos. 103, 25251-25261.

Barnes, J.D., Sharp, Z.D., Fischer, T.P., Hilton, D.R., Carr, M.J., 2009. Chlorine isotope variations along the Central American volcanic front and back arc. Geochem. Geophys. Geosyst. 10 (11).

Beaudry, P., Longpre, M.-A., Economos, R., Wing, B.A., Bui, T.H., Stix, J., 2018. Degassing-induced fractionation of multiple Sulphur isotopes unveils post-Archaean recycled oceanic crust signal in hotspot lava. Nat. Commun. 9, 5093.

Benjamin, E.R., Plank, T., Wade, J.A., Kelley, K.A., Hauri, E.H., Alvarado, G.E., 2007. High water contents in basaltic magmas from Irazú Volcano, Costa Rica. J. Volcanol. Geotherm. Res. 168 (1-4), 68-92.

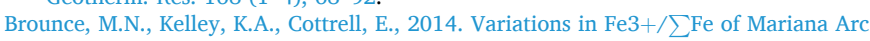
Basalts and Mantle Wedge fO2. J. Petrol. 55, 2513-2536.

Brounce, M., Kelley, K.A., Cottrell, E., Reagan, M.K., 2015. Temporal evolution of mantle wedge oxygen fugacity during subduction initiation. Geology 43, 775-778.

Canfield, D.E., 2004. The evolution of the Earth surface sulfur reservoir. Am. J. Sci. 304 839-861.

Carr, M.J., Feigenson, M.D., Bennett, E.A., 1990. Incompatible element and isotopic evidence for tectonic control of source mixing and melt extraction along the CentralAmerican Arc. Contrib. Mineral. Petrol. 105, 369-380.

Carr, M.J., Feigenson, M.D., Bolge, L.L., Walker, J.A., Gazel, E., 2014. RU _ CAG eochem, a database and sample repository for Central American volcanic rocks at Rutgers University. Geosci. Data J. 1, 43-48.

Clift, P., Vannucchi, P., 2004. Controls on tectonic accretion versus erosion in subduction zones: Implications for the origin and recycling of the continental crust. Rev. Geophys. 42 (2).

Daag, A.S., Tubianosa, B.S., Newhall, C.G., Tungol, N.M., Javier, D., Dolan, M.T., Delos Reyes, P.J., Arboleda, R.A., Martinez, M.L., Regalado, T.M., 1996. Monitoring sulfur dioxide emission at Mount Pinatubo. Fire and Mud: eruptions and lahars of Mount Pinatubo, Philippines, pp. 409-414.

de Moor, J.M., 2013. Magmatic Volatiles at Rifts and Arcs: Sources and Fractionation Effects, 334 pp. University of New Mexico, Albuquerque. https://digitalrepository. unm.edu/eps_etds/16/.

de Moor, J.M., Fischer, T.P., Sharp, Z.D., Hauri, E.H., Hilton, D.R., Atudorei, V., 2010. Sulfur isotope fractionation during the May 2003 eruption of Anatahan volcano Mariana Islands: implications for sulfur sources and plume processes. Geochim. Cosmochim. Acta 74 (18), 5382-5397.

de Moor, J.M., Fischer, T.P., Sharp, Z.D., King, P.L., Wilke, M., Botcharnikov, R.E., Cottrell, E., Zelenski, M., Marty, B., Klimm, K., Rivard, C., Ayalew, D., Ramirez, C. 2013. Sulfur degassing at Erta Ale (Ethiopia) and Masaya (Nicaragua): Implications for degassing processes and oxygen fugacities of basaltic systems. Geochem. Geophys. Geosyst. https://doi.org/10.1002/ggge.20255.

de Moor, J.M., Aiuppa, A., Avard, G., Wehrmann, H., Dunbar, N., Muller, C. Tamburello, G., Giudice, G., Liuzzo, M., Moretti, R., Conde, V., 2016b. Turmoil at Turrialba Volcano (Costa Rica): Degassing and eruptive processes inferred from high-frequency gas monitoring. J. Geophys. Res. Solid Earth 121 (8), 5761-5775.

de Moor, J.M., Aiuppa, A., Pacheco, J., Avard, G., Kern, C., Liuzzo, M., Martinez, M., Giudice, G., Fischer, T.P., 2016a. Short-period volcanic gas precursors to phreatic eruptions: Insights from Poás Volcano. Costa Rica Earth Planet. Sci. Lett. 442, 218-227. https://doi.org/10.1016/j.epsl.2016.1002.1056.

de Moor, J. M., C. Kern, G. Avard, C. Muller, A. Aiuppa, A. Saballos, M. Ibarra, P. LaFemina, M. Protti, and T. P. Fischer (2017), A new sulfur and carbon degassing inventory for the Southern Central American Volcanic Arc: the importance of accurate time series datasets and implications for global volatile budgets, Geochem. Geophys. Geosyst., 18, 4437-4468. doi:44https://doi.org/10.1002/2017GC007141.

Delavault, H., Chauvel, C., Thomassot, E., Devey, C.W., Dazas, B., 2016. Sulfur and lead isotopic evidence of relic Archean sediments in the Pitcairn mantle plume. Proc. Natl. Acad. Sci. 113 (46), 12952-12956.

Dottin III, J.W., Labidi, J., Lekic, V., Jackson, M.G., Farquhar, J., 2020. Sulfur isotope characterization of primordial and recycled sources feeding the Samoan mantle plume. Earth Planet. Sci. Lett. 534, 116073.

Elkins, L.J., Fischer, T.P., Hilton, D.R., Sharp, Z.D., McKnight, S., Walker, J., 2006. Tracing nitrogen in volcanic and geothermal volatiles from the Nicaraguan volcanic front. Geochim. Cosmochim. Acta 70, 5215-5235.

Evans, K.A., 2012. The redox budget of subduction zones. Earth Sci. Rev. 113, 11-32.

Evans, K.A., Tomkins, A.G., 2011. The relationship between subduction zone redox budget and arc magma fertility. Earth Planet. Sci. Lett. 308, 401-409.

Evans, K.A., Tomkins, A.G., Cliff, J., Fiorentini, M.L., 2014. Insights into subduction zone sulfur recycling from isotopic analysis of eclogite-hosted sulfides. Chem. Geol. 365, $1-19$.

Fischer, T.P., 2008. Fluxes of volatiles (H2O, CO2, N2, Cl, F) from arc volcanoes. Geochem. J. 42, 21-38.

Fischer, T.P., Hilton, D.R., Zimmer, M.M., Shaw, A.M., Sharp, Z.D., Walker, J.A., 2002. Subduction and recycling of nitrogen along the central American margin. Science 297, 1154-1157.

Freundt, A., Grevemeyer, I., Rabbel, W., Hansteen, T.H., Hensen, C., Wehrmann, H., Kutterolf, S., Halama, R., Frische, M., 2014. Volatile (H2O, CO2, Cl, S) budget of the
Central American subduction zone. Int. J. Earth Sci. 103, 2101-2127. https://doi. org/10.1007/s00531-00014-01001-00531.

Gazel, E., Carr, M.J., Hoernle, K., Feigenson, M.D., Szymanski, D., Hauff, F., van den Bogaard, P.C.Q.S., 2009. Galapagos-OIB signature in southern Central America: Mantle refertilization by arc-hot spot interaction. Geochem. Geophys. Geosyst. 10.

Gazel, E., Flores, K.E., Carr, M.J., 2021. Architectural and tectonic control on the segmentation of the Central American Volcanic Arc. Annu. Rev. Earth Planet. Sci. 49.

Giggenbach, W.F., 1996. Chemical composition of volcanic gas. In: Tilling, R. (Ed.), IAVCEI-UNESCO: Monitoring and Mitigation of Volcanic Hazards. Springer-Verlag, Berlin Heidelberg, pp. 221-256.

Giggenbach, W.F., Goguel, R.L., 1989. Methods for the Collection and Analysis of Geothermal and Volcanic Water and Gas Samples, vol. 53. Chem. Div., Dept. of Sci. and Ind.Res., Petone, New Zealand.

GlobalVolcanismProgram, 2013. Volcanoes of the World. In: v. 4.5.6., edited by E. Venzke. Smithsonian Institution. https://doi.org/10.5479/si.GVP.VOTW5474-2013.

Grevemeyer, I., Ranero, C.R., Flueh, E.R., Kläschen, D., Bialas, J., 2007. Passive and active seismological study of bending-related faulting and mantle serpentinization at the Middle America trench. Earth Planet. Sci. Lett. 258 (3-4), 528-542.

Henley, R.W., Fischer, T.P., 2021. Sulfur sequestration and redox equilibria in volcanic gases. J. Volcanol. Geotherm. Res. 107181.

Hilton, D.R., Fischer, T.P., Marty, B., 2002. Noble gases and volatile recycling at subduction zones. In: Noble Gases in Geochemistry and Cosmochemistry, pp. 319-370 edited by D. Porcelli, et al.

Hilton, D.R., Ramirez, C.J., Mora-Amador, R., Fischer, T.P., Füri, E., Barry, P.H., Shaw, A. M., 2010. Monitoring of temporal and spatial variations in fumarole helium and carbon dioxide characteristics at Poás and Turrialba volcanoes, Costa Rica (20012009). Geochem. J. 44 (5), 431-440.

Holloway, J.R., Blank, J.G., 1994. Application of experimental results to C-O-H species in natural melts. In: Carroll, M.R., Holloway, J.R. (Eds.), Volatiles in Magmas. Mineralogical Society of America, Fredericksburg, pp. 187-230.

Kagoshima, T., Sano, Y., Takahata, N., Maruoka, T., Fischer, T.P., Hattori, K., 2015. Sulphur geodynamic cycle. Sci. Rep. 5, 8330.

Kelley, K.A., Cottrell, E., 2009. Water and the oxidation state of subduction zone magmas. Science 325, 605-607.

Kimura, G., Silver, E.A., Blum, P., et al., 1997. Proceedings of the ocean drilling program, Initial Reports, Vol. 170, Site 1040.

Kurtz, A.C., Kump, L.R., Arthur, M.A., Zachos, J.C., Paytan, A., 2003. Early Cenozoic decoupling of the global carbon and sulfur cycles. Paleoceanography 18 (4).

Kutterolf, S., Freundt, A., Perez, W., 2008. Pacific offshore record of plinian arc volcanism in Central America: 2. Tephra volumes and erupted masses, Geochemistry, Geophysics. Geosystems 9.

Labidi, J., Cartigny, P., Birck, J.L., Assayag, N., Bourrand, J.J., 2012. Determination of multiple sulfur isotopes in glasses: a reappraisal of the MORB 834 S. Chem. Geol. 334, 189-198.

Labidi, J., Cartigny, P., Jackson, M.G., 2015. Multiple sulfur isotope composition of oxidized Samoan melts and the implications of a sulfur isotope 'mantle array'in chemical geodynamics. Earth Planet. Sci. Lett. 417, 28-39.

Labidi, J., Cartigny, P., Moreira, M., 2013. Non-chondritic sulphur isotope composition of the terrestrial mantle. Nature 501 (7466), 208-211.

Lee, C.-T.A., Luffi, P., Chin, E.J., Bouchet, R., Dasgupta, R., Morton, D.M., Le Roux, V., Yin, Q.-Z., Jin, D., 2012. Copper Systematics in Arc Magmas and Implications for Crust-Mantle Differentiation. Science 336, 64-68.

Lee, C.-T.A., Erdman, M., Yang, W., Ingram, L., Chin, E.J., DePaolo, D.J., 2018. Sulfur isotopic compositions of deep arc cumulates. Earth Planet. Sci. Lett. 500, 76-85.

Marini, L., Moretti, R., Accornero, M., 2011. Sulfur isotopes in magmatic-hydrothermal systems, melts, and magmas. In: Behrens, H., Webster, J.D. (Eds.), Sulfur in Magmas and Melts: Its Importance for Natural and Technical Processes. The Mineralogical Society of America, Chantilly, Virginia, pp. 423-492.

Mather, T.A., McCabe, J.R., Rai, V.K., Thiemens, M.H., Pyle, D.M., Heaton, T.H.E., Sloane, H.J., Fern, G.R., 2006a. Oxygen and sulfur isotopic composition of volcanic sulfate aerosol at the point of emission. J. Geophys. Res.-Atmos. 111.

Mather, T.A., Pyle, D.M., Tsanev, V.I., McGonigle, A.J.S., Oppenheimer, C., Allen, A.G., 2006b. A reassessment of current volcanic emissions from the central American arc with specific examples from Nicaragua. J. Volcanol. Geotherm. Res. 149, 297-311.

McDonough, W.F., Sun, S.S., 1995. The composition of the Earth. Chem. Geol. 120, 223-253.

Menyailov, I.A., Nikitina, L.P., Shapar, V.N., Pilipenko, V.P., 1986. Temperature increase and chemical change of fumarolic gases at Momotombo volcano, Nicaragua, in 1982-1985: are these indicators of a possible eruption? J. Geophys. Res. Solid Earth 91 (B12), 12199-12214.

Mori, T., Shinohara, H., Kazahaya, K., Hirabayashi, J.I., Matsushima, T., Mori, T., Ohwada, M., Odai, M., Iino, H., Miyashita, M., 2013. Time-averaged SO2 fluxes of subduction-zone volcanoes: example of a 32-year exhaustive survey for Japanese volcanoes. J. Geophys. Res.-Atmos. 118 (15), 8662-8674.

Oppenheimer, C., Fischer, T.P., Scaillet, B., 2014. Volcanic degassing: process and impact. In: Treatise on Geochemistry (Second Edition), 4, pp. 111-179.

Patino, L.C., Carr, M.J., Feigenson, M.D., 2000. Local and regional variations in central American arc lavas controlled by variations in subducted sediment input. Contrib. Mineral. Petrol. 138, 265-283.

Peacock, S.M., van Keken, P.E., Holloway, S.D., Hacker, B.R., Abers, G.A., Fergason, R.L., 2005. Thermal structure of the Costa Rica-Nicaragua subduction zone. Phys. Earth Planet. Inter. 149 (1-2), 187-200.

Plank, T., Balzer, V., Carr, M., 2002. Nicaraguan volcanoes record paleoceanographic changes accompanying closure of the Panama gateway. Geology 30, 1087-1090. 
Protti, M., Gu, F., McNally, K., 1994. The geometry of the Wadati-Benioff zone under southern Central America and its tectonic significance: results from a high-resolution local seismographic network. Phys. Earth Planet. Inter. 84 (1-4), 271-287.

Rielli, A., Tomkins, A.G., Nebel, O., Brugger, J., Etschmann, B., Zhong, R., Yaxley, G.M. Paterson, D., 2017. Evidence of sub-arc mantle oxidation by Sulphur and carbon. Geochem. Perspect. Lett. 3, 124-132.

Robidoux, P., Aiuppa, A., Rotolo, S.G., Rizzo, A.L., Hauri, E.H., Frezzotti, M.L., 2017a. Volatile contents of mafic-to-intermediate magmas at San Cristóbal volcano in Nicaragua. Lithos 272, 147-163.

Robidoux, P., Rotolo, S.G., Aiuppa, A., Lanzo, G., Hauri, E.H., 2017b. Geochemistry and volatile content of magmas feeding explosive eruptions at Telica volcano (Nicaragua). J. Volcanol. Geotherm. Res. 341, 131-148.

Robinson, B.W., 1995. Sulphur Isotope Standards, 825. International Atomic Energy Agency TECDOC, pp. 39-45.

Roggensack, K., Hervig, R.L., McKnight, S.B., Williams, S.N., 1997. Explosive basaltic volcanism from Cerro Negro volcano: influence of volatiles on eruptive style. Science 277 (5332), 1639-1642.

Rose, W.I., Stoiber, R.E., Malinconico, L.L., 1982. Eruptive gas compositions and fluxes of explosive volcanoes: Budget of $\mathrm{S}$ and $\mathrm{Cl}$ emitted from Fuego volcano, Guatemala. In: Thorpe, R.S. (Ed.), Andesites: Orogenic Andesites and Related Rocks. Wiley, New York NY, pp. 669-676.

Rowe, G.L., 1994. Oxygen, hydrogen, and sulfur isotope systematics of the crater lake system of Poas volcano, Costa-Rica. Geochem. J. 28, 263-287.

Rüpke, L.H., Morgan, J.P., Hort, M., Connolly, J.A.D., 2002. Are the regional variations in central American arc lavas due to differing basaltic versus peridotitic slab sources of fluids? Geology 30, 1035-1038.

Sakai, H., Des Marais, D.J., Ueda, A., Moore, J.G., 1984. Concentrations and isotope ratios of carbon, nitrogen and sulfur in ocean-floor basalts. Geochim. Cosmochim. Acta 48 (12), 2433-2441.

Shaw, A.M., Hilton, D.R., Fischer, T.P., Walker, J.A., Alvarado, G.E., 2003. Contrasting He-C relationships in Nicaragua and Costa Rica: insights into C cycling through subduction zones. Earth Planet. Sci. Lett. 214 (3-4), 499-513.

Shinohara, H., 2008. Excess degassing from volcanoes and its role on eruptive and intrusive activity. Rev. Geophys. 46 (4).

Shinohara, H., 2013. Volatile flux from subduction zone volcanoes: insights from a detailed evaluation of the fluxes from volcanoes in Japan. J. Volcanol. Geotherm. Res. 268, 46-63.

Sigurdsson, H., 1990. Assessment of the atmospheric impact of volcanic eruptions. In: Global Catastrophes in Earth History, pp. 99-110 edited by V. I. Sharpton and P. D. Ward. Geol. Soc. Am. Spec. Pap.

Smit, K.V., Shirey, S.B., Hauri, E.H., Stern, R.A., 2019. Sulfur isotopes in diamonds reveal differences in continent construction. Science 364 (6438), 383-385.

Solomon, E.A., Kastner, M., 2012. Progressive barite dissolution in the Costa Rica forearc: Implications for global fluxes of Ba to the volcanic arc and mantle. Geochim. Cosmochim. Acta 83, 110-124.

Stern, R.J., Kohut, E., Bloomer, S.H., Leybourne, M., Fouch, M., Vervoort, J., 2006. Subduction factory processes beneath the Guguan cross-chain, Mariana Arc: no role for sediments, are serpentinites important? Contrib. Mineral. Petrol. 151, 202-221. https://doi.org/10.1007/s00410-005-0055-2.

Stoiber, R.E., Williams, S.N., Huebert, B., 1987. Annual contribution of sulfur dioxide to the atmosphere by volcanoes. J. Volcanol. Geother. Res. 33 (1-3), 1-8.

Strauss, H., 1997. The isotopic composition of sedimentary sulfur through time. Palaeogeogr. Palaeoclimatol. Palaeoecol. 132, 97-118.
Sun, W., Huang, R.-f., Li, H., Hu, Y.-b., Zhang, C.-c., Sun, S.-j., Zhang, L.-p., Ding, X., Li, C.-y., Zartman, R.E., 2015. Porphyry deposits and oxidized magmas. Ore Geol. Rev. 65, 97-131.

Syracuse, E.M., Abers, G.A., 2006. Global compilation of variations in slab depth beneath arc volcanoes and implications. Geochem. Geophys. Geosyst. 7 (5).

Taracsák, Z., Neave, D.A., Beaudry, P., Gunnarsson-Robin, J., Burgess, R., Edmonds, M., Halldórsson, S.A., Longpré, M.A., Ono, S., Ranta, E., Stefánsson, A., 2021. Instrumental mass fractionation during sulfur isotope analysis by secondary ion mass spectrometry in natural and synthetic glasses. Chem. Geol. 578, 120318.

Taran, Y.A., Hedenquist, J.W., Korzhinsky, M.A., Tkachenko, S.I., Shmulovich, K.I., 1995. Geochemistry of magmatic gases from Kudryavy Volcano, Iturup, Kuril Islands. Geochim. Cosmochim. Acta 59, 1749-1761.

Teagle, D.A.H., Alt, J.C., Umino, S., Miyashita, S., Banerjee, N.R., Wilson, D.S., the Expedition 309/312 Scientists, 2006. Proc. IODP, 309/312: Washington, DC (Integrated Ocean Drilling Program Management International, Inc.), pp. 1-549. https://doi.org/10.2204/iodp.proc.309312.103.2006.

Tomkins, A.G., Evans, K.A., 2015. Separate zones of sulfate and sulfide release from subducted mafic oceanic crust. Earth Planet. Sci. Lett. 428, 73-83.

Van Avendonk, H.J., Holbrook, W.S., Lizarralde, D., Denyer, P., 2011. Structure and serpentinization of the subducting Cocos plate offshore Nicaragua and Costa Rica. Geochem. Geophys. Geosyst. 12 (6).

Vannucchi, P., Scholl, D.W., Meschede, M., McDougall, K., 2001. Tectonic erosion and consequent collapse of the Pacific margin of Costa Rica: combined implications from ODP Leg 170, seismic offshore data, and regional geology of the Nicoya Peninsula. Tectonics 20 (5), 649-668.

Vannucchi, P., Ranero, C.R., Galeotti, S., Straub, S.M., Scholl, D.W., McDougall-Ried, K., 2003. Fast rates of subduction erosion along the Costa Rica Pacific margin: Implications for nonsteady rates of crustal recycling at subduction zones. J. Geophys. Res. Solid Earth 108 (B11).

Wade, J.A., Plank, T., Melson, W.G., Soto, G.J., Hauri, E.H., 2006. The volatile content of magmas from Arenal volcano, Costa Rica. J. Volcanol. Geotherm. Res. 157 (1-3), 94-120.

Wallace, P.J., 2005. Volatiles in subduction zone magmas: concentrations and fluxes based on melt inclusion and volcanic gas data. J. Volcanol. Geotherm. Res. 140 (1-3), 217-240.

Walters, J.B., Cruz-Uribe, A.M., Marschall, H.R., 2020. Sulfur loss from subducted altered oceanic crust and implications for mantle oxidation. Geochem. Perspect. Lett. 13, $36-41$.

Walther, C.H., 2003. The crustal structure of the Cocos ridge off Costa Rica. J. Geophys. Res. Solid Earth 108 (B3).

Walther, C.H.E., Flueh, E.R., Ranero, C.R., Von Huene, R., Strauch, W., 2000. Crustal structure across the Pacific margin of Nicaragua: evidence for ophiolitic basement and a shallow mantle sliver. Geophys. J. Int. 141 (3), 759-777.

Williams, S.N., Sturchio, N.C., Mendez, R., Londoño, A., García, N., 1990. Sulfur dioxide from Nevado del Ruiz volcano, Colombia: total flux and isotopic constraints on its origin. J. Volcanol. Geotherm. Res. 42 (1-2), 53-68.

Workman, R.K., Hart, S.R., 2005. Major and trace element composition of the depleted MORB mantle (DMM). Earth Planet. Sci. Lett. 231 (1-2), 53-72.

Ye, S., Bialas, J., Flueh, E.R., Stavenhagen, A., von Huene, R., 1996. Crustal structure of the Middle American Trench off Costa Rica from wide-angle seismic data. Tectonics 15, 1006-1021. https://doi.org/10.1029/96TC00827.

Zimmer, M.M., Fischer, T.P., Hilton, D.R., Alvarado, G.E., Sharp, Z.D., Walker, J.A., 2004. Nitrogen systematics and gas fluxes of subduction zones: insights from Costa Rica arc volatiles. Geochem. Geophys. Geosyst. 5 (5). 